\title{
Promise of retinoic acid-triazolyl derivatives in promoting neurite Promise of retinoic acid-triazolyl derivatives in promoting differentiation of neuroblastoma cells
}

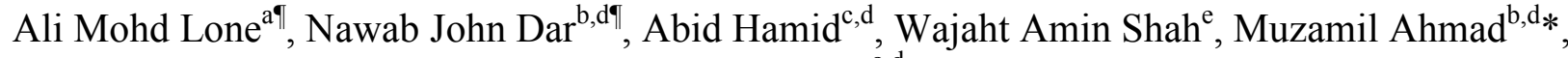 \\ Bilal A. Bhat ${ }^{\mathrm{a}, \mathrm{d} *}$ \\ ${ }^{a}$ Medicinal Chemistry Division, CSIR-Indian Institute of Integrative Medicine, Sanatnagar-Srinagar 190005, Jammu \& Kashmir, India \\ ${ }^{b}$ Neuropharmacology Division, CSIR-Indian Institute of Integrative Medicine, Sanatnagar-Srinagar 190005, Jammu \& Kashmir, India \\ ${ }^{\mathrm{c}}$ Cancer Pharmacology Division, CSIR-Indian Institute of Integrative Medicine, Jammu 180001, India \\ ${ }^{\mathrm{d}}$ Academy of Scientific and Innovative Research, CSIR-Indian Institute of Integrative Medicine, Canal Road, Jammu 180001, India. \\ ${ }^{\text {e}}$ Department of Chemistry, University of Kashmir, Srinagar 190006, India \\ "These authors contributed equally to this work.
}

CORRESPONDING AUTHOR

*To whom correspondence should be addressed; Fax: +91-194244133; Tel: +91-1942431253/55; E-mail: mahmad@iiim.ac.in(MA); bilal@iiim.ac.in (BAB). 
${ }^{1} \mathrm{H}$ NMR $\left(400 \mathrm{MHz}, \mathrm{CDCl}_{3}\right)$ and ${ }^{13} \mathrm{C} \mathrm{NMR}\left(100 \mathrm{MHz}, \mathrm{CDCl}_{3}\right)$ of 7

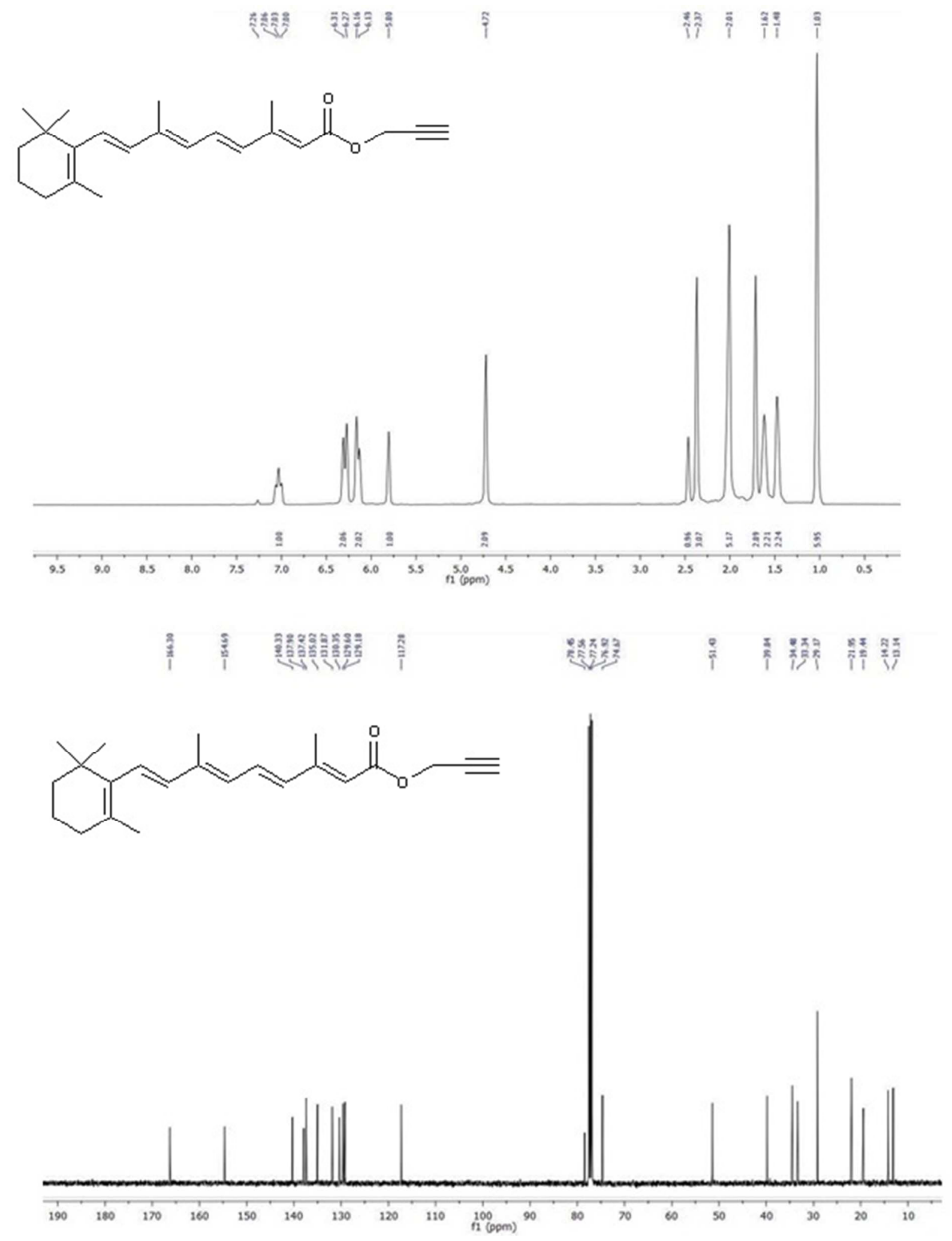



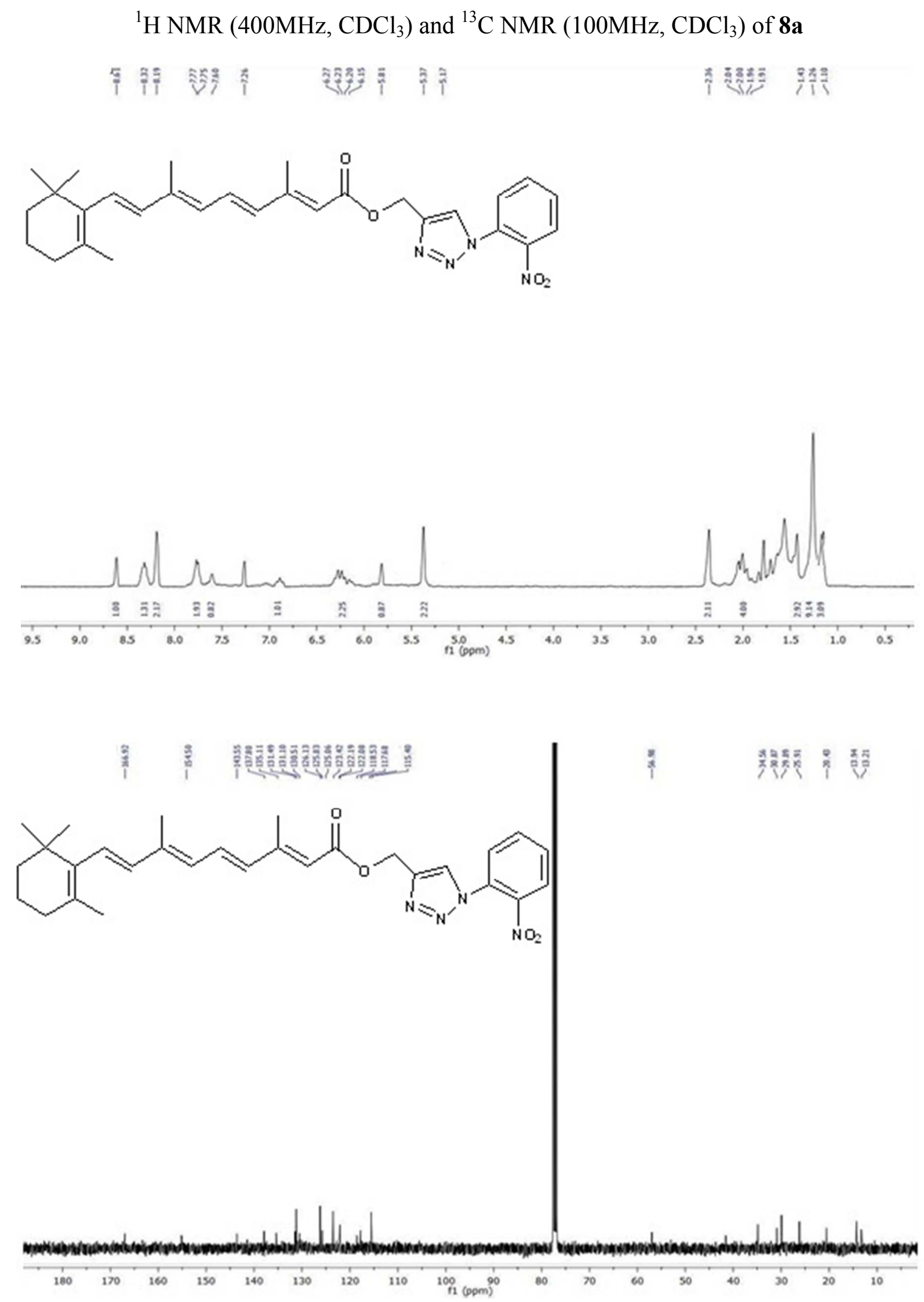
${ }^{1} \mathrm{H}$ NMR $\left(400 \mathrm{MHz}, \mathrm{CDCl}_{3}\right)$ and ${ }^{13} \mathrm{C}$ NMR $\left(100 \mathrm{MHz}, \mathrm{CDCl}_{3}\right)$ of $\mathbf{8 b}$

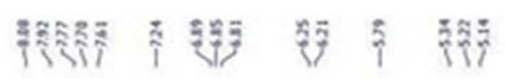

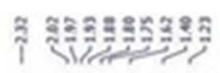<smiles></smiles>

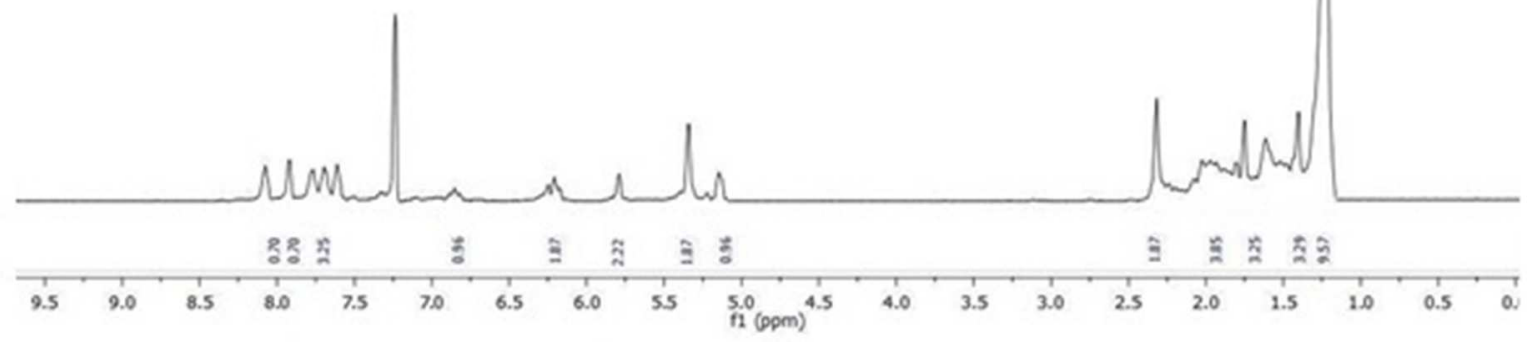

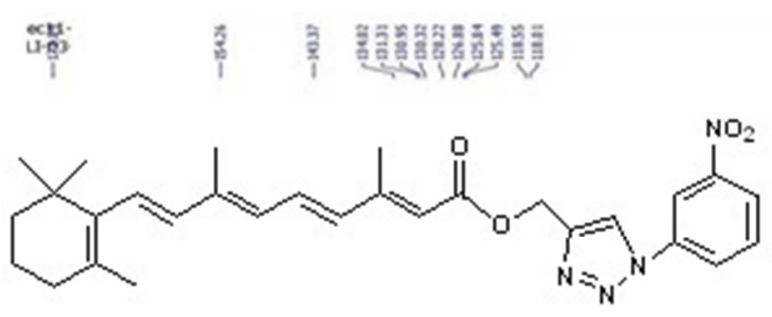

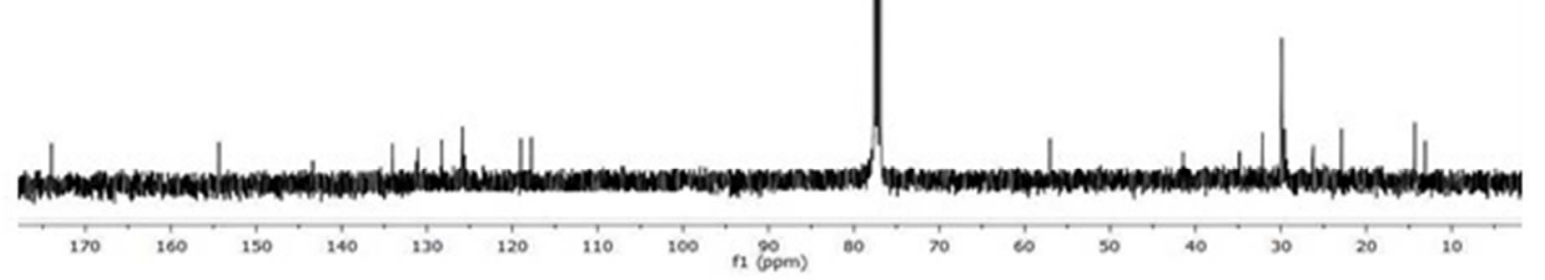


${ }^{1} \mathrm{H}$ NMR $\left(400 \mathrm{MHz}, \mathrm{CDCl}_{3}\right)$ and ${ }^{13} \mathrm{C} \mathrm{NMR}\left(100 \mathrm{MHz}, \mathrm{CDCl}_{3}\right)$ of $\mathbf{8 c}$

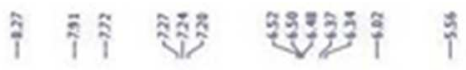

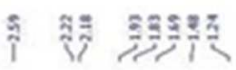

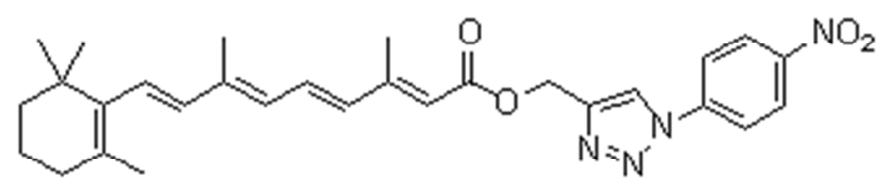

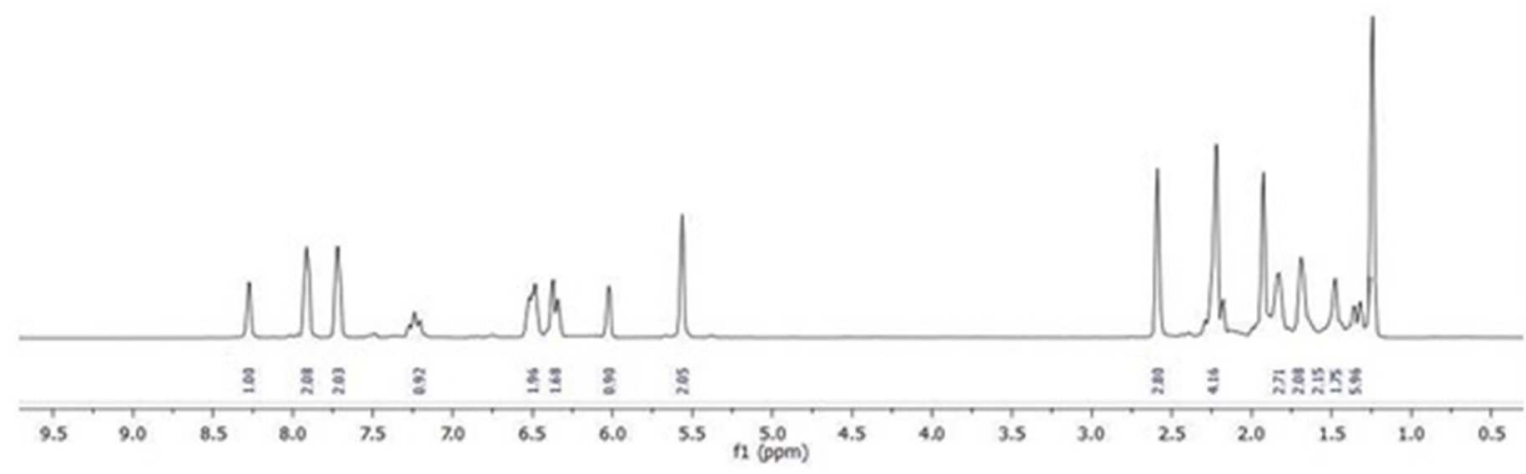

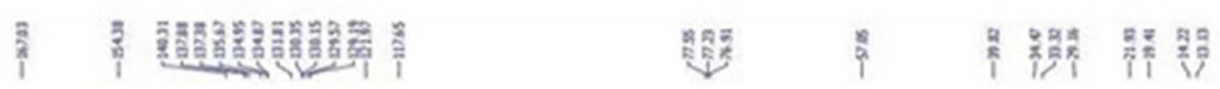<smiles></smiles>

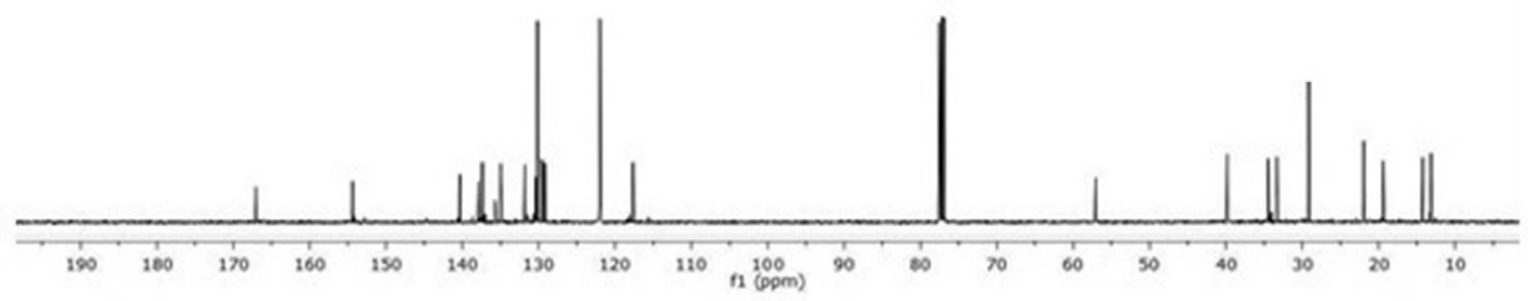


${ }^{1} \mathrm{H}$ NMR $\left(400 \mathrm{MHz}, \mathrm{CDCl}_{3}\right)$ and ${ }^{13} \mathrm{C} \mathrm{NMR}\left(100 \mathrm{MHz}, \mathrm{CDCl}_{3}\right)$ of $\mathbf{8 d}$ ิิ

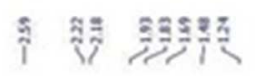<smiles>CC1=C(/C=C/C(C)=C/C=C/C(C)=C/C(=O)OCc2cn(-c3ccc(Br)cc3)nn2)C(C)(C)CCC1</smiles>

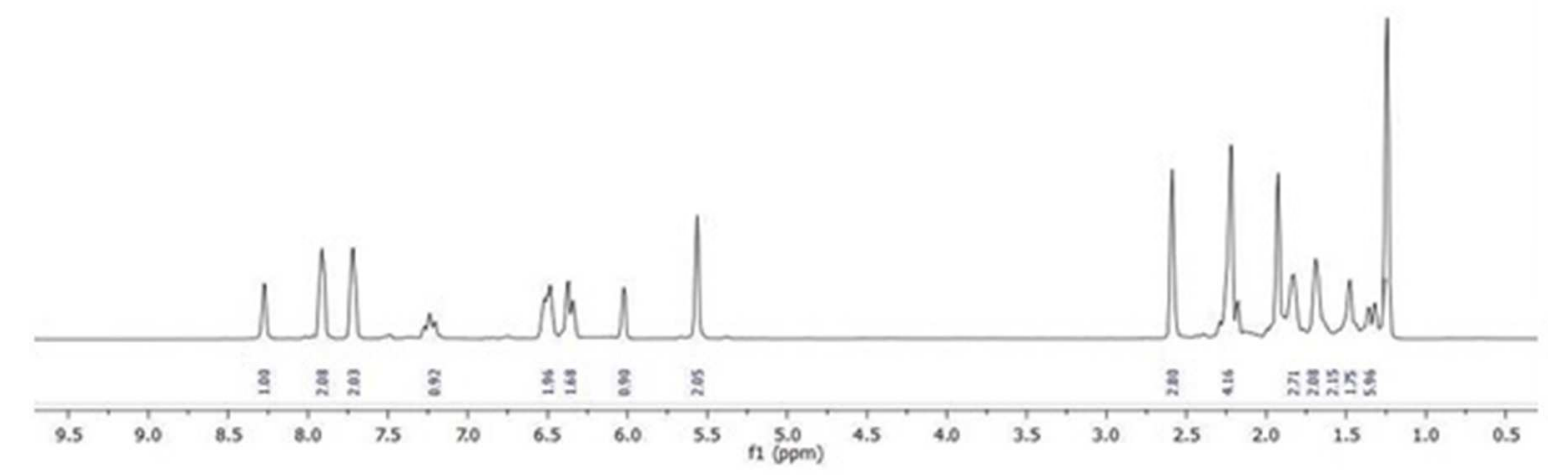

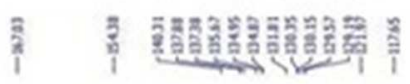

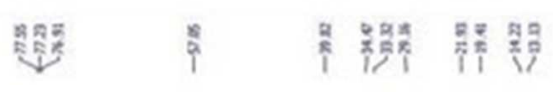<smiles>CC1=C(/C=C/C(C)=C/C=C/C(C)=C/C(=O)OCc2cn(-c3ccc(Br)cc3)nn2)C(C)(C)CCC1</smiles>

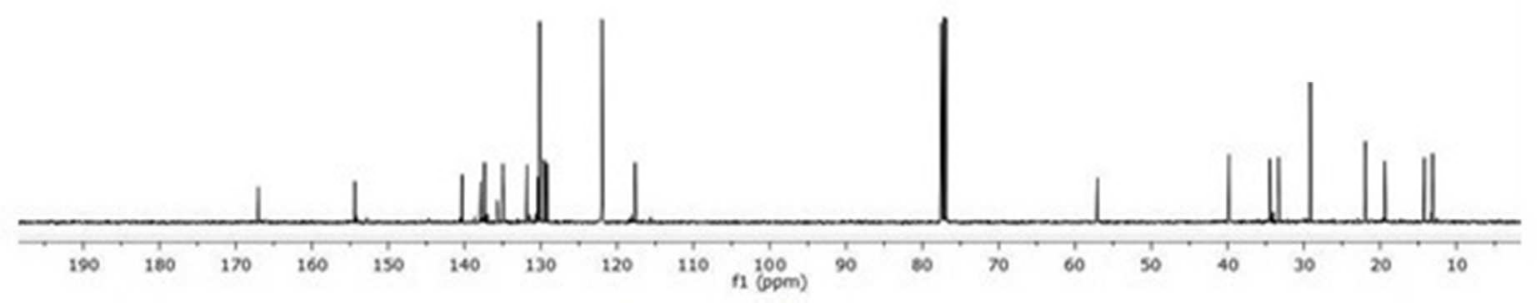


${ }^{1} \mathrm{H}$ NMR $\left(400 \mathrm{MHz}, \mathrm{CDCl}_{3}\right)$ and ${ }^{13} \mathrm{C}$ NMR $\left(100 \mathrm{MHz}, \mathrm{CDCl}_{3}\right)$ of $\mathbf{8 e}$

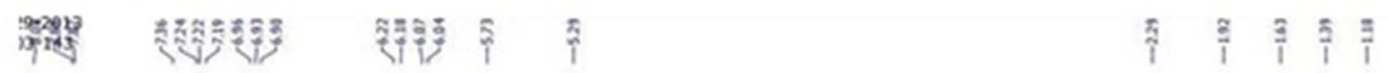<smiles>CC1=C(/C=C/C(C)=C/C=C/C(C)=C/C(=O)OCc2cn(-c3ccccc3F)nn2)C(C)(C)CCC1</smiles>

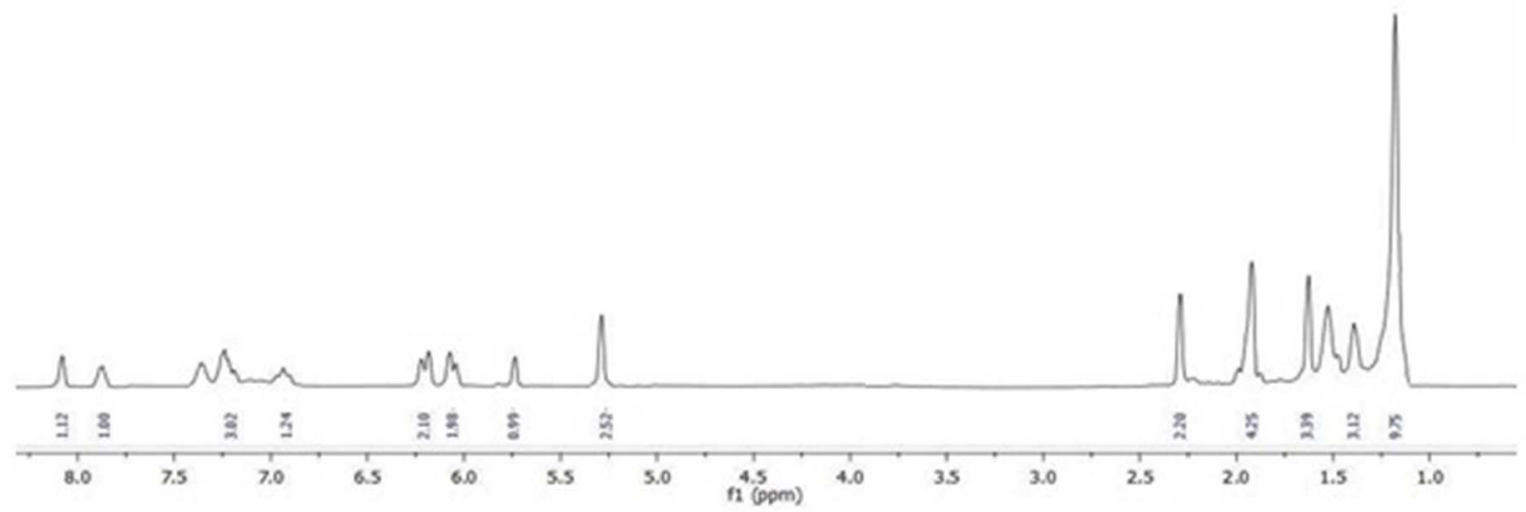

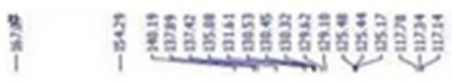

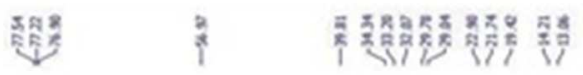

When

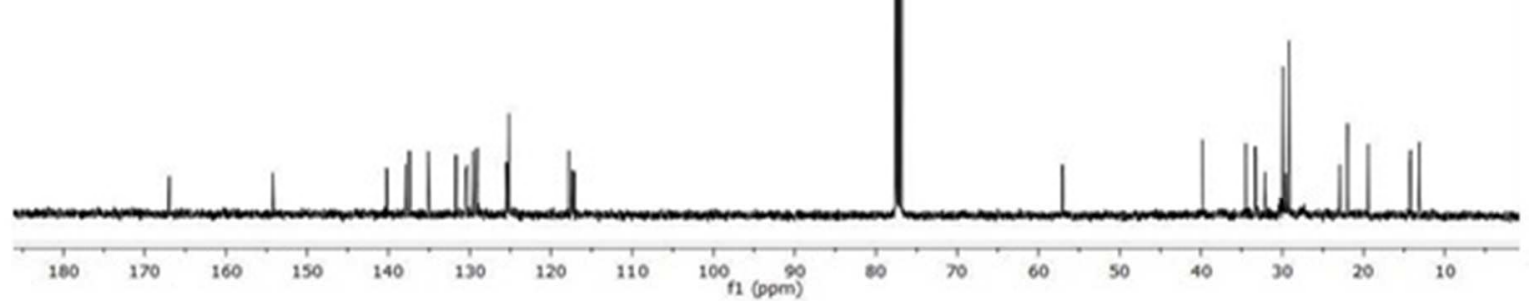


${ }^{1} \mathrm{H} \mathrm{NMR}\left(400 \mathrm{MHz}, \mathrm{CDCl}_{3}\right)$ and ${ }^{13} \mathrm{C} \mathrm{NMR}\left(100 \mathrm{MHz}, \mathrm{CDCl}_{3}\right)$ of $\mathbf{8 f}$

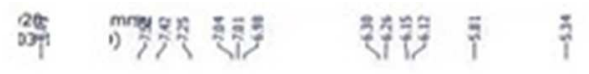

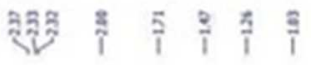<smiles>CC1=C(/C=C/C(C)=C/C=C/C(C)=C/C(=O)OCc2cn(-c3ccc(F)cc3F)nn2)C(C)(C)CCC1</smiles>

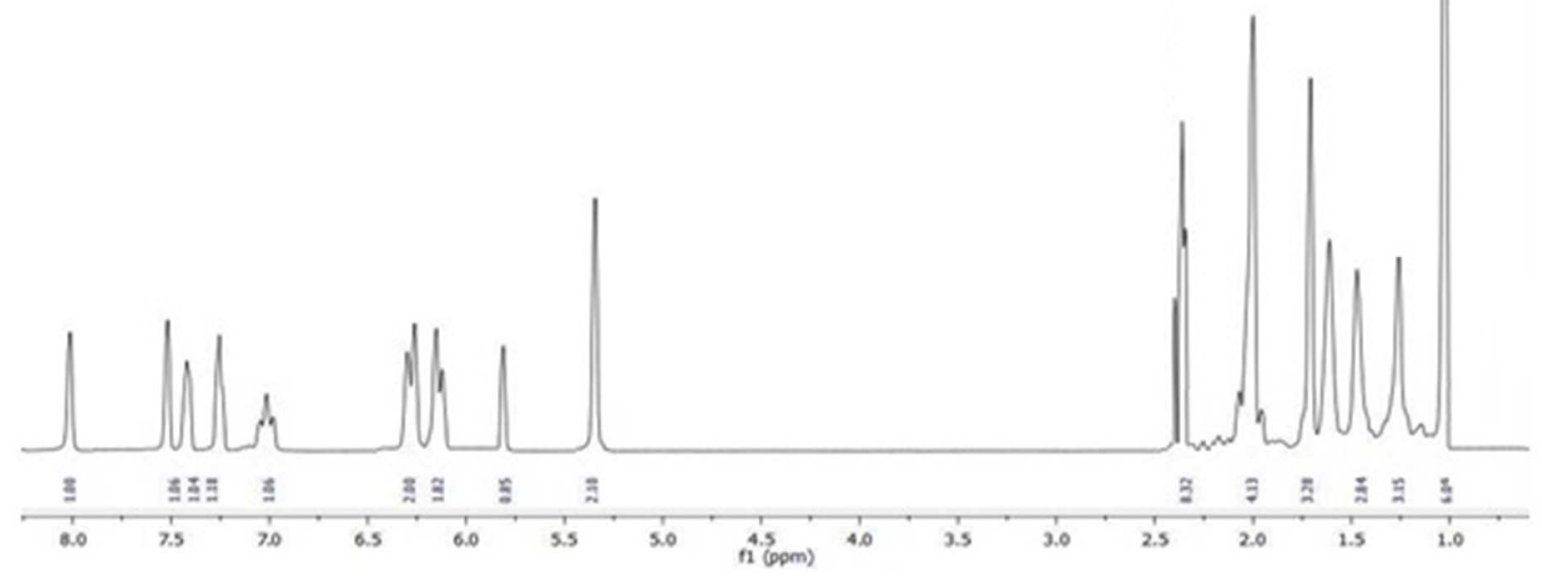

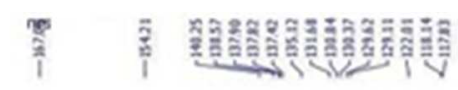

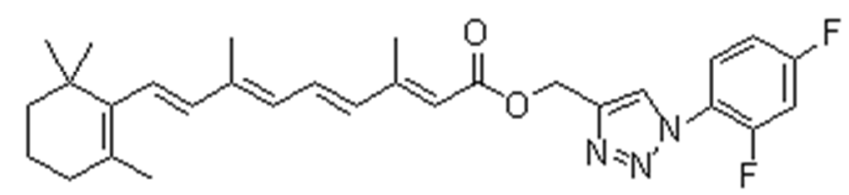

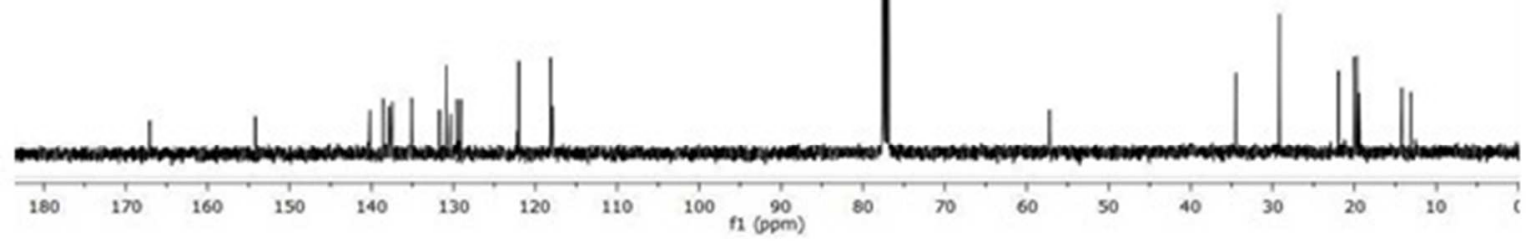


${ }^{1} \mathrm{H}$ NMR $\left(400 \mathrm{MHz}, \mathrm{CDCl}_{3}\right)$ and ${ }^{13} \mathrm{C} \mathrm{NMR}\left(100 \mathrm{MHz}, \mathrm{CDCl}_{3}\right)$ of $\mathbf{8 g}$

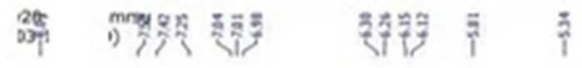

悬<smiles>CC1=C(/C=C/C(C)=C/C=C/C(C)=C/C(=O)OCc2cn(-c3ccc(C)c(C)c3)nn2)C(C)(C)CCC1</smiles>

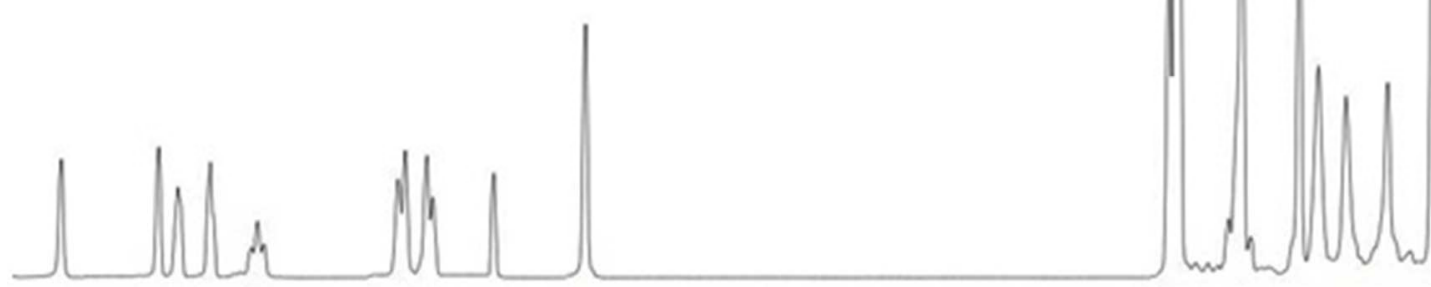

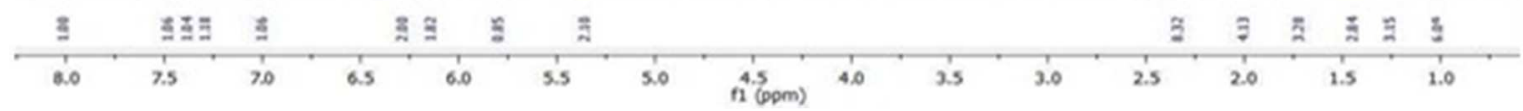

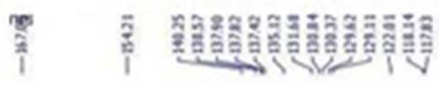

U1
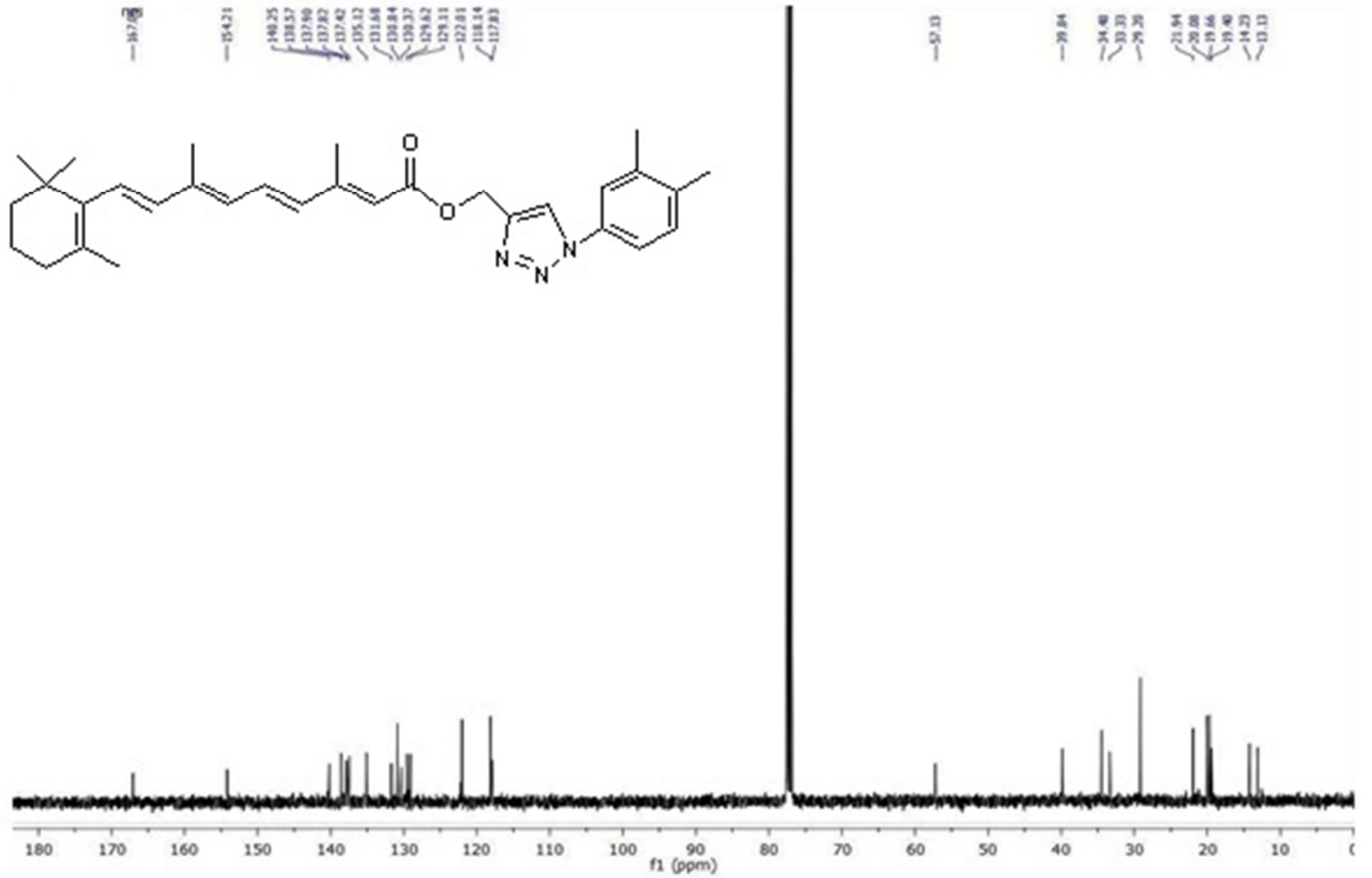
${ }^{1} \mathrm{H}$ NMR $\left(400 \mathrm{MHz}, \mathrm{CDCl}_{3}\right)$ and ${ }^{13} \mathrm{C} \mathrm{NMR}\left(100 \mathrm{MHz}, \mathrm{CDCl}_{3}\right)$ of $\mathbf{8 h}$
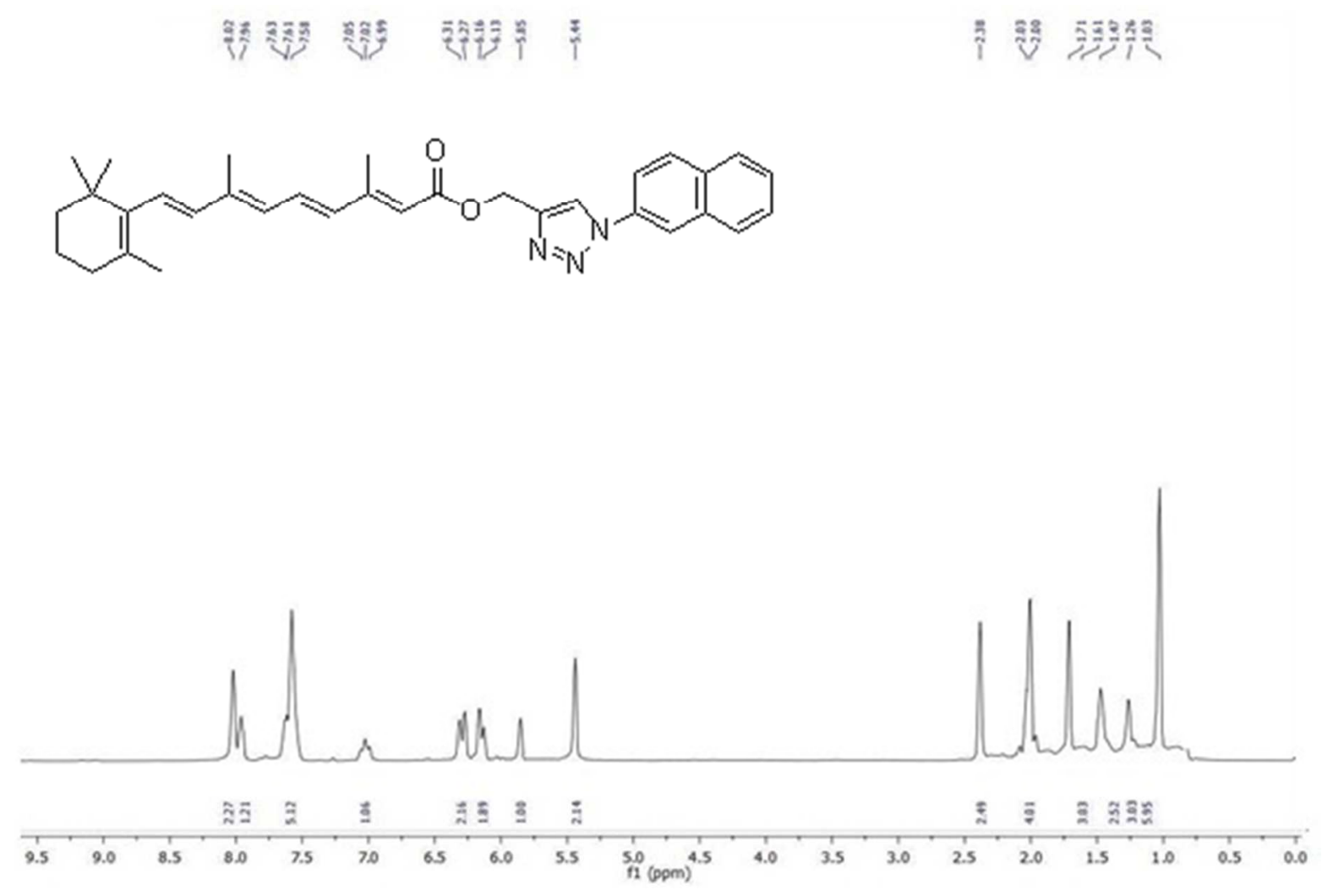

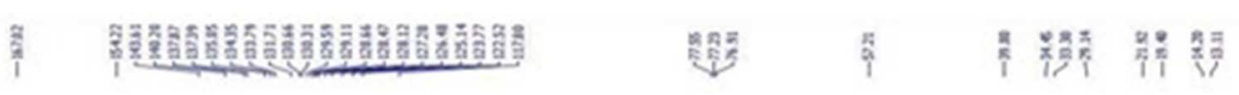<smiles>CC1=C(/C=C/C(C)=C/C=C/C(C)=C/C(=O)OCc2cn(-c3ccc4ccccc4c3)nn2)C(C)(C)CCC1</smiles>

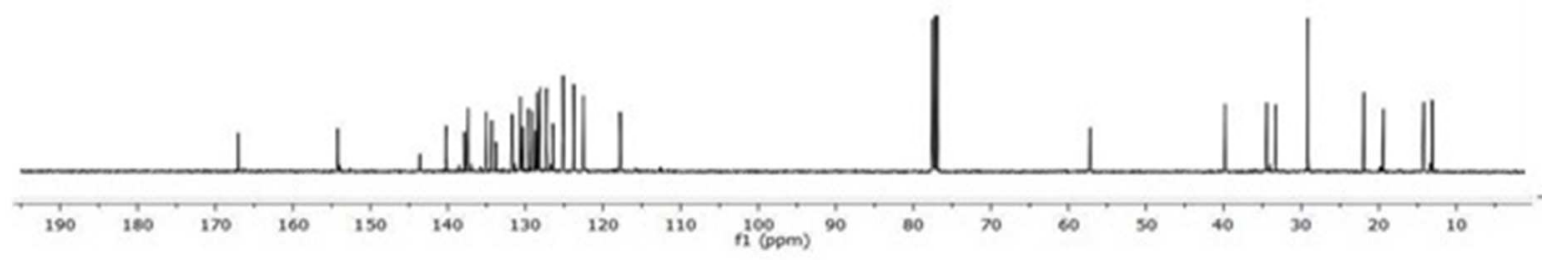


${ }^{1} \mathrm{H}$ NMR $\left(400 \mathrm{MHz}, \mathrm{CDCl}_{3}\right)$ and ${ }^{13} \mathrm{C}$ NMR $\left(100 \mathrm{MHz}, \mathrm{CDCl}_{3}\right)$ of $\mathbf{8 j}$

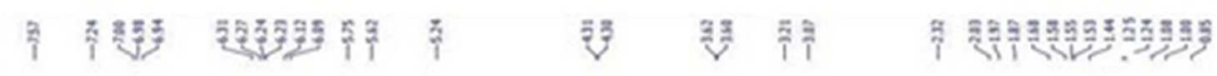<smiles>CC1=C(/C=C/C(C)=C/C=C/C(C)=C/C(=O)OCc2cn(Cc3ccccc3)nn2)C(C)(C)CCC1</smiles>
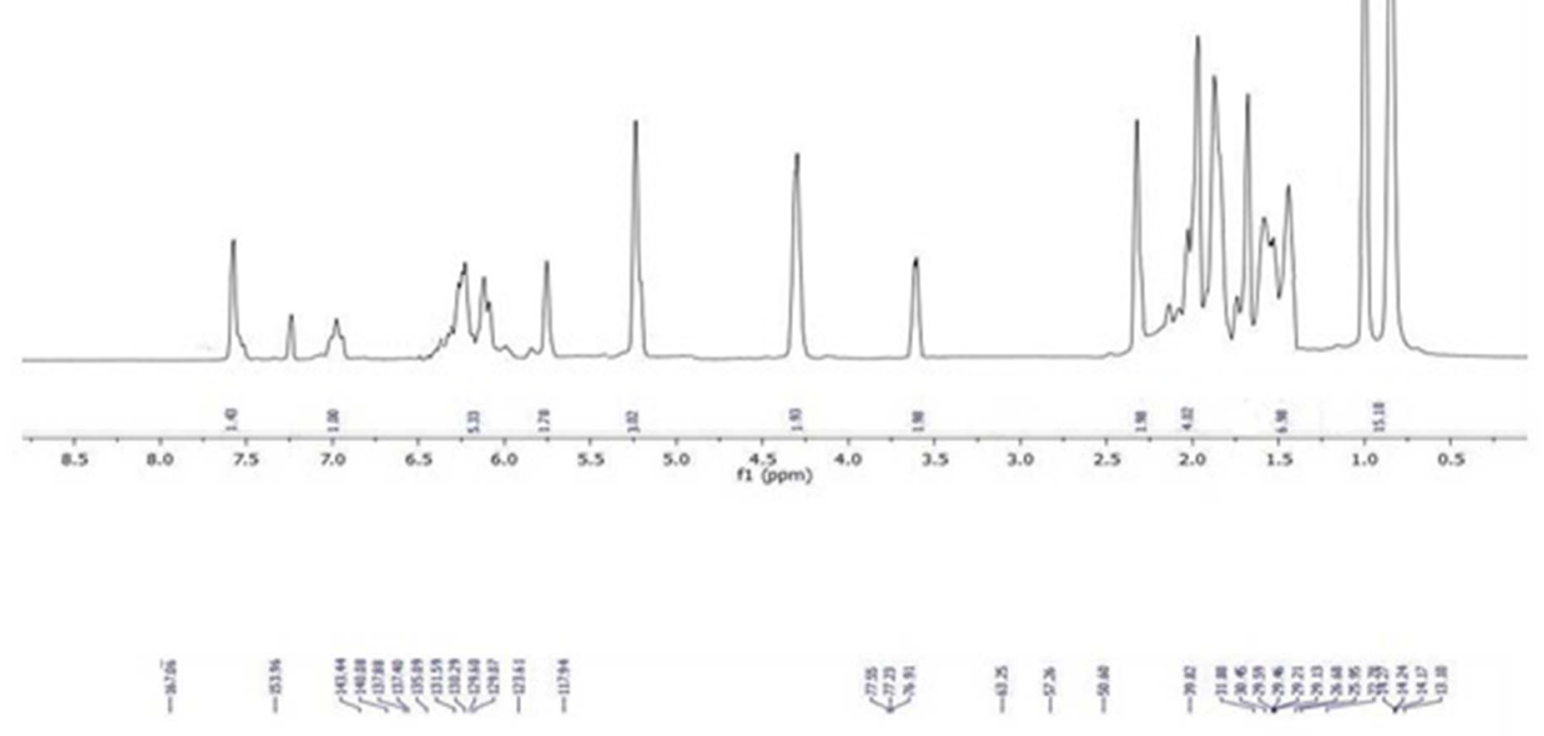<smiles>CC1=C(/C=C/C(C)=C/C=C/C(C)=C/C(=O)OCc2cn(Cc3ccccc3)nn2)C(C)(C)CCC1</smiles>

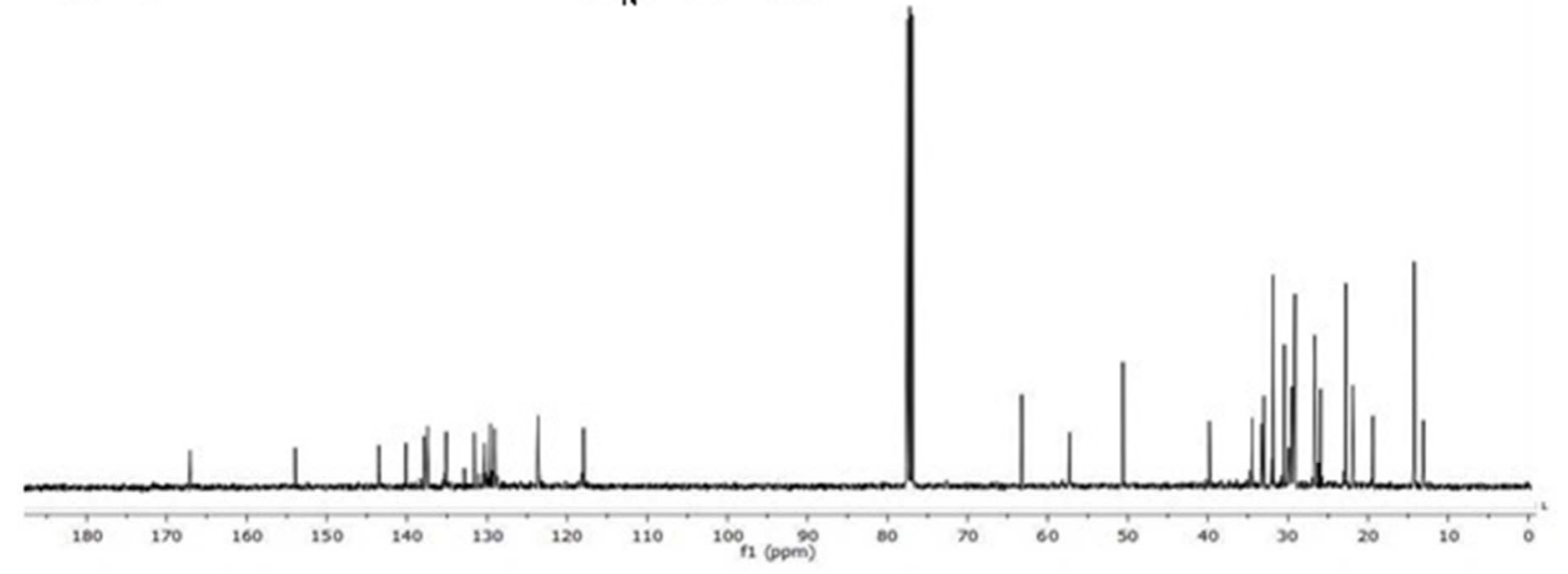


${ }^{1} \mathrm{H}$ NMR $\left(400 \mathrm{MHz}, \mathrm{CDCl}_{3}\right)$ and ${ }^{13} \mathrm{C} \mathrm{NMR}\left(100 \mathrm{MHz}, \mathrm{CDCl}_{3}\right)$ of $\mathbf{8 k}$

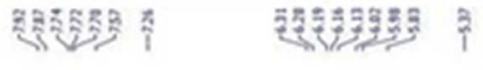

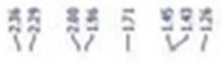

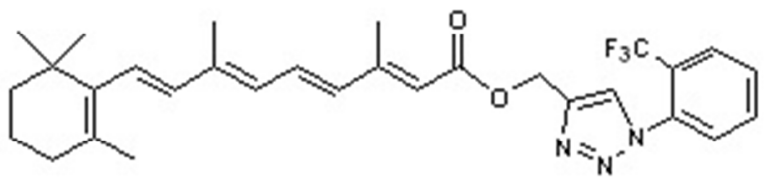
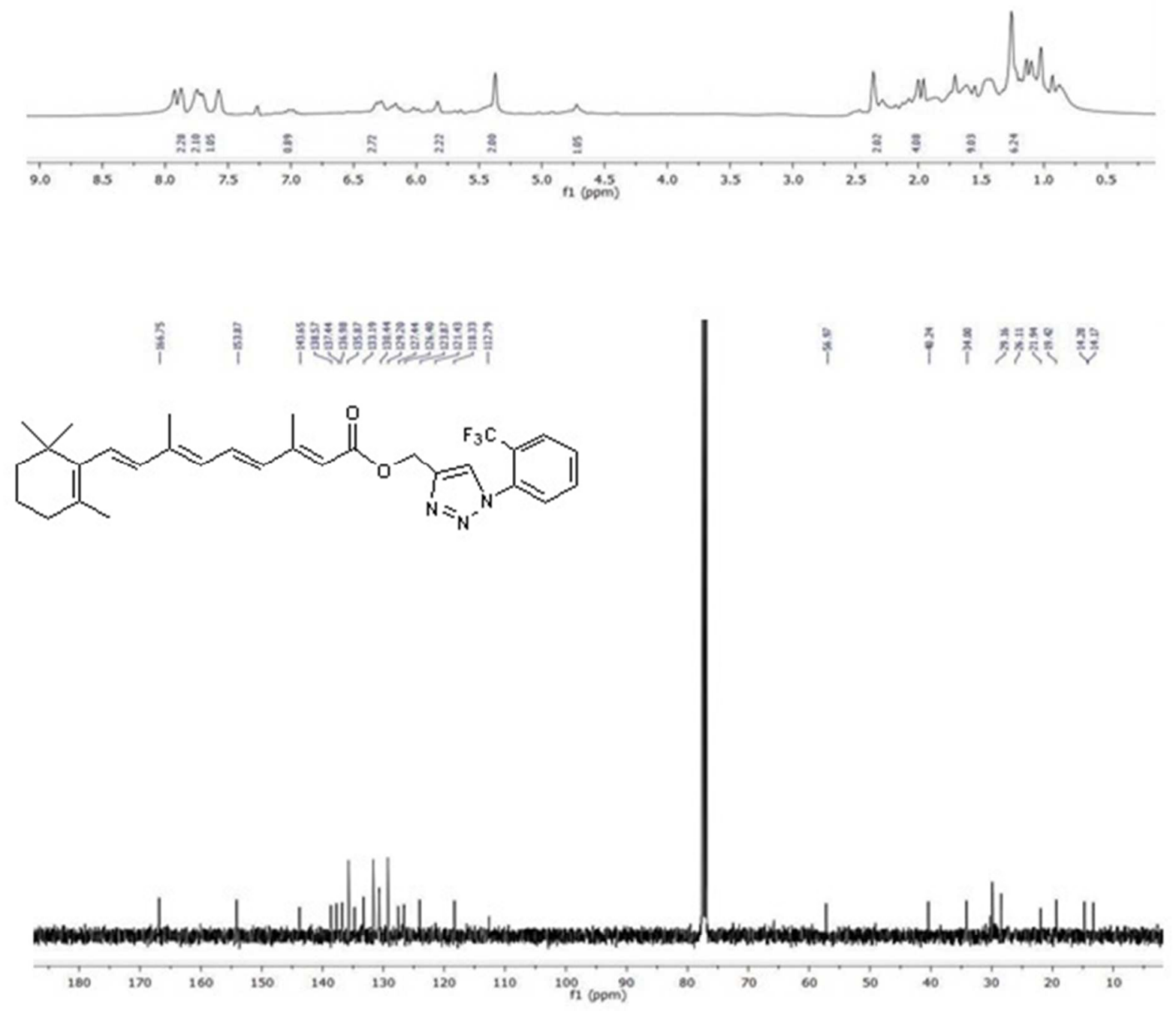
${ }^{1} \mathrm{H}$ NMR $\left(400 \mathrm{MHz}, \mathrm{CDCl}_{3}\right)$ and ${ }^{13} \mathrm{C} \mathrm{NMR}\left(100 \mathrm{MHz}, \mathrm{CDCl}_{3}\right)$ of $\mathbf{8} \mathbf{I}$

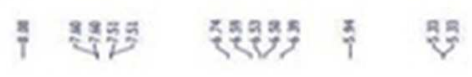

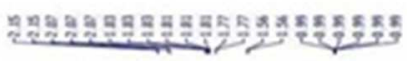<smiles>CC1=C(/C=C/C(C)=C/C=C/C(C)=C/C(=O)OCc2cn(-c3ccc(Cl)cc3)nn2)C(C)(C)CCC1</smiles>

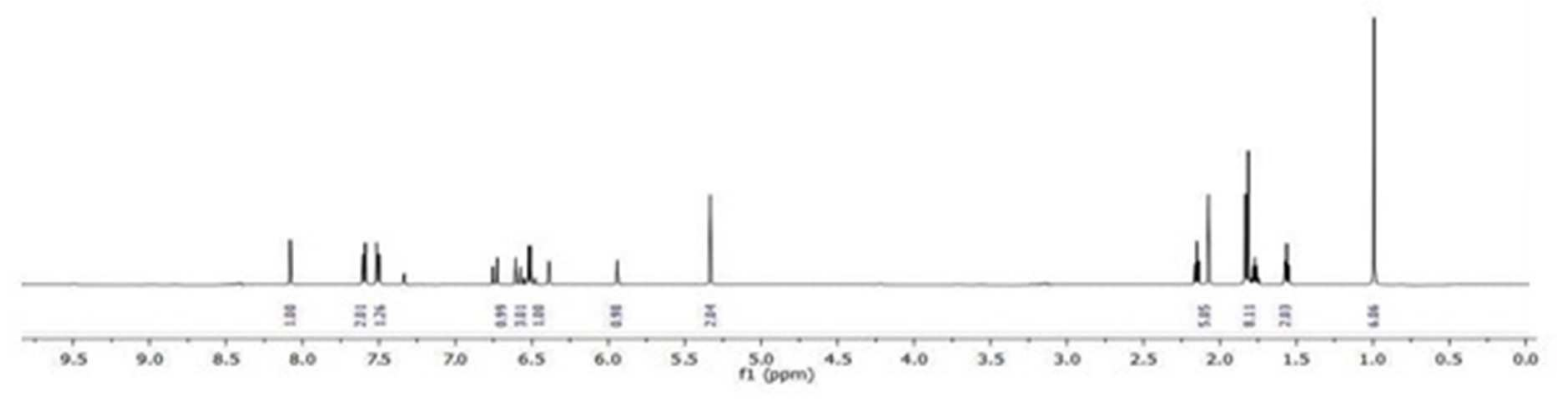

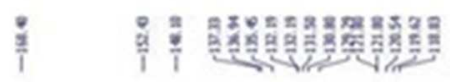<smiles>CC1=C(/C=C/C(C)=C/C=C/C(C)=C/C(=O)OCc2cn(-c3ccc(Cl)cc3)nn2)C(C)(C)CCC1</smiles>

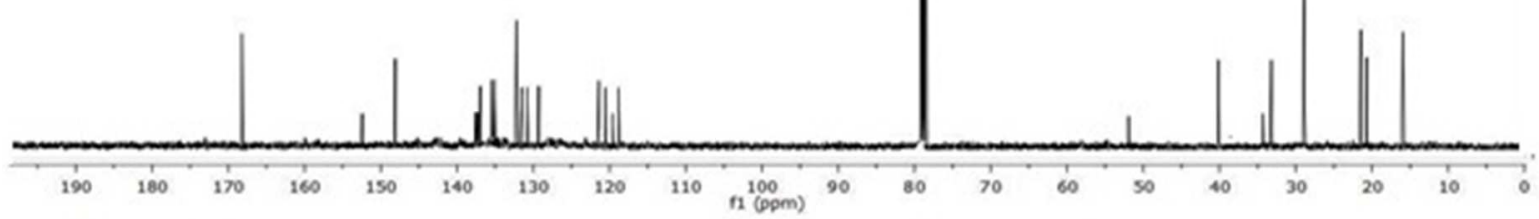


${ }^{1} \mathrm{H}$ NMR $\left(400 \mathrm{MHz}, \mathrm{CDCl}_{3}\right)$ and ${ }^{13} \mathrm{C} \mathrm{NMR}\left(100 \mathrm{MHz}, \mathrm{CDCl}_{3}\right)$ of $\mathbf{8 m}$

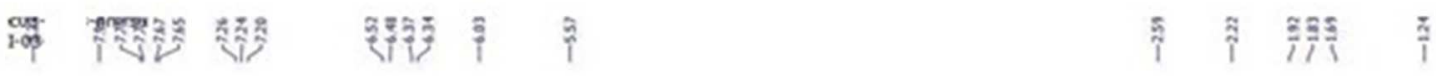<smiles>CC1=C(/C=C/C(C)=C/C=C/C(C)=C/C(=O)OCc2cn(-c3c(Cl)cc(Cl)cc3Cl)nn2)C(C)(C)CCC1</smiles>

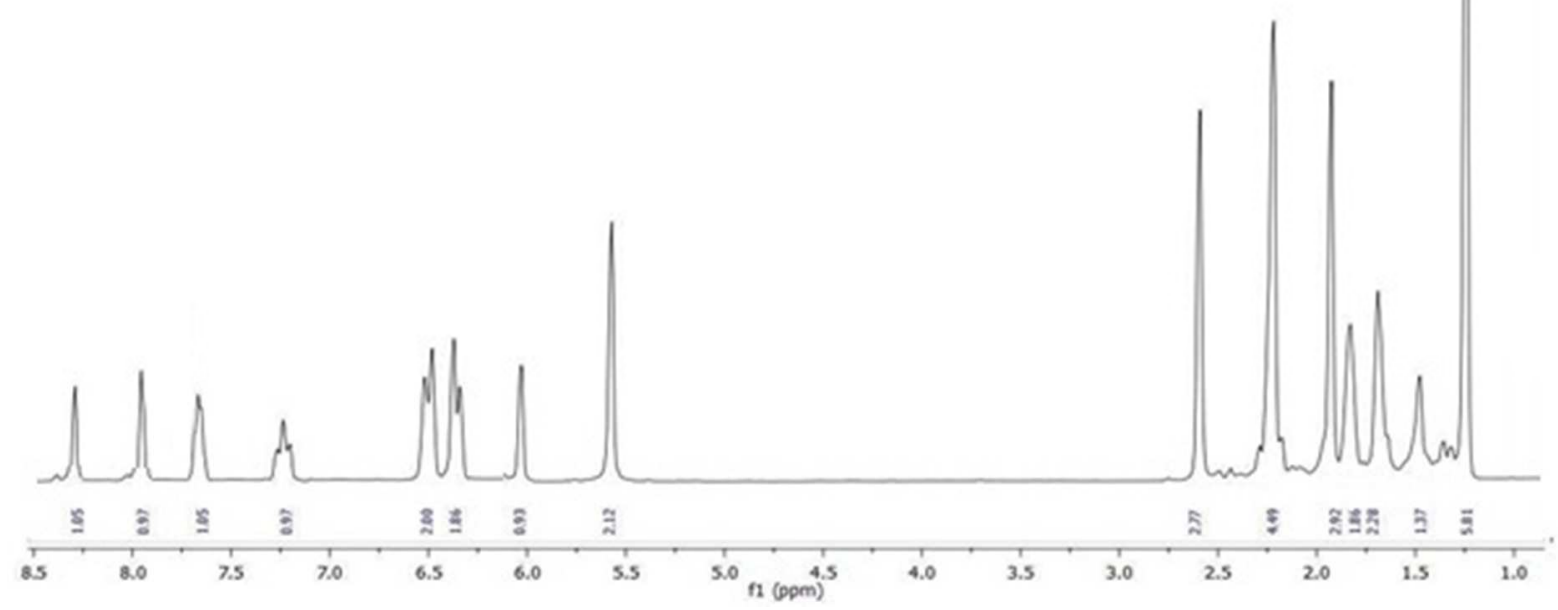

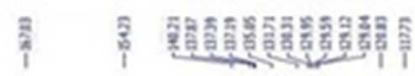

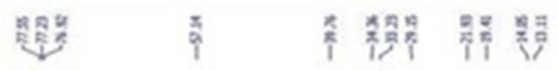<smiles>CC1=C(/C=C/C(C)=C/C=C/C(C)=C/C(=O)OCc2cn(-c3c(Cl)cc(Cl)cc3Cl)nn2)C(C)(C)CCC1</smiles>

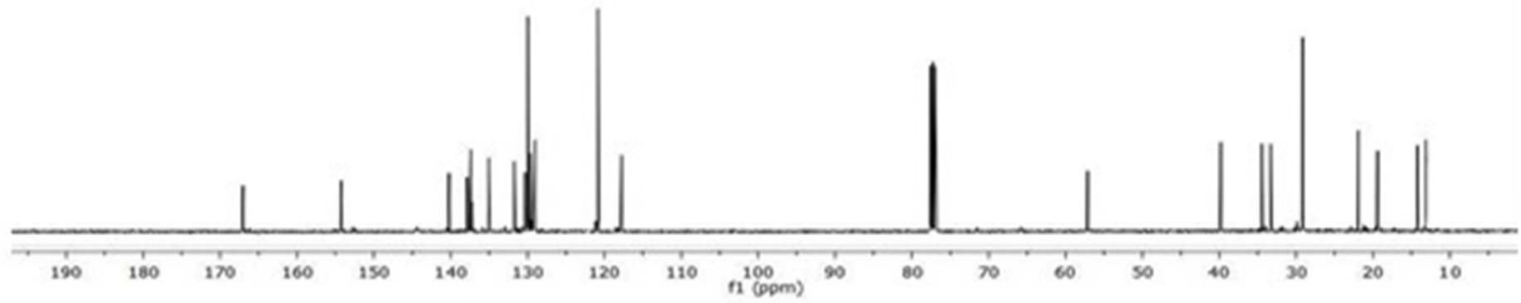


${ }^{1} \mathrm{H}$ NMR $\left(400 \mathrm{MHz}, \mathrm{CDCl}_{3}\right)$ and ${ }^{13} \mathrm{C} \mathrm{NMR}\left(100 \mathrm{MHz}, \mathrm{CDCl}_{3}\right)$ of $\mathbf{8 n}$

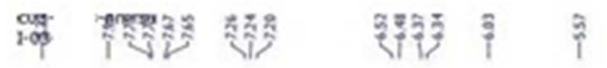

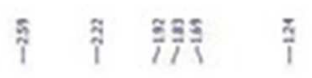

YNAl

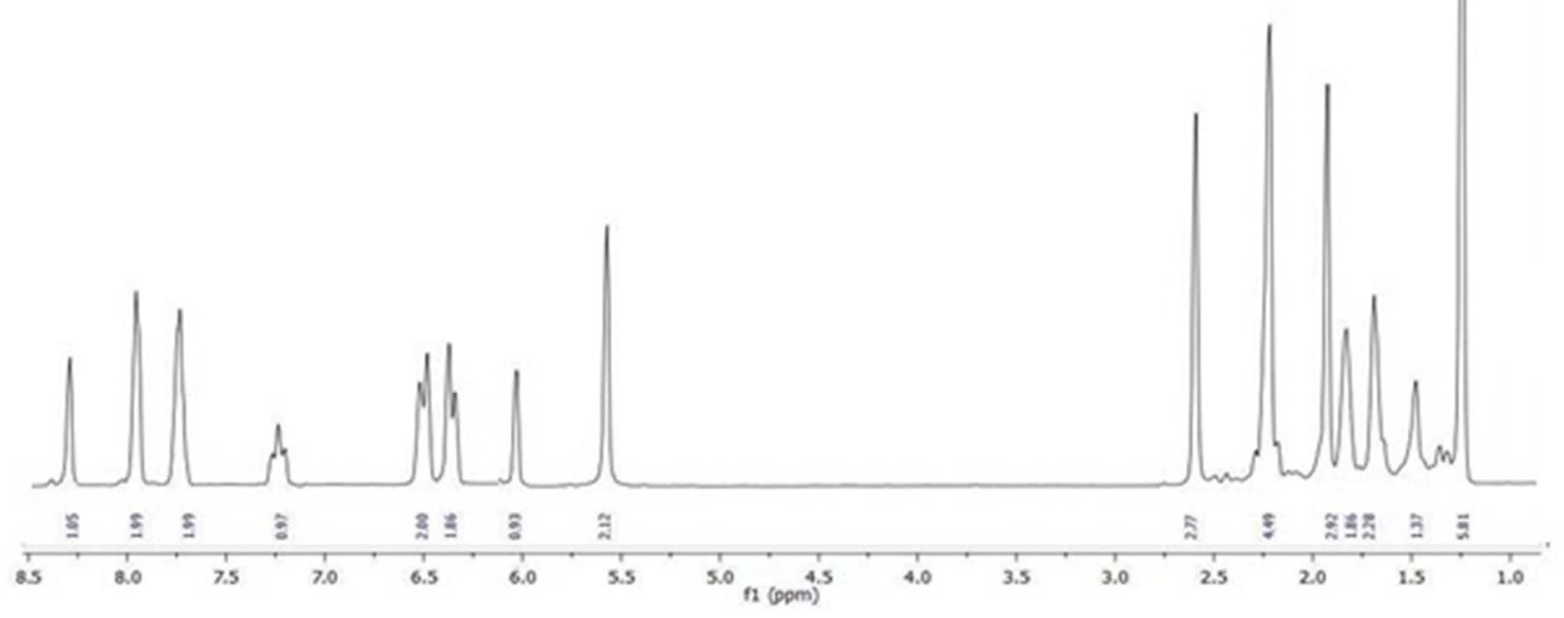

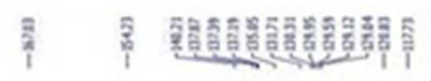

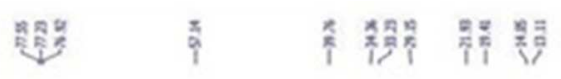<smiles>CC1=C(/C=C/C(C)=C/C=C/C(C)=C/C(=O)OCc2cn(-c3ccccc3Br)nn2)C(C)(C)CCC1</smiles>

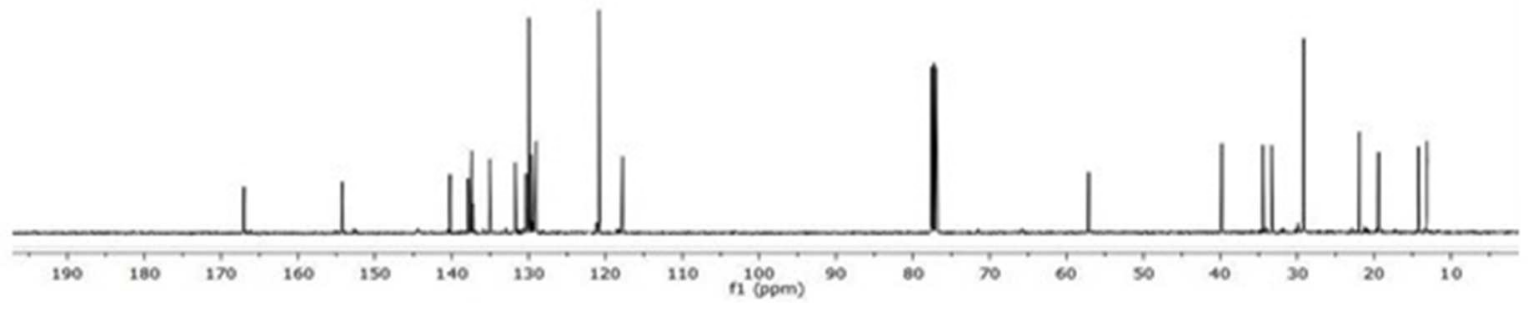


${ }^{1} \mathrm{H} \mathrm{NMR}\left(400 \mathrm{MHz}, \mathrm{CDCl}_{3}\right)$ and ${ }^{13} \mathrm{C} \mathrm{NMR}\left(100 \mathrm{MHz}, \mathrm{CDCl}_{3}\right)$ of 80

率i

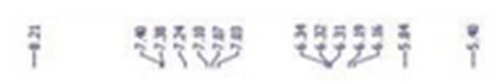
i<smiles>CC1=C(/C=C/C(C)=C/C=C/C(C)=C/C(=O)OCc2cn(-c3cc(Cl)ccc3C(=O)O)nn2)C(C)(C)CCC1</smiles>

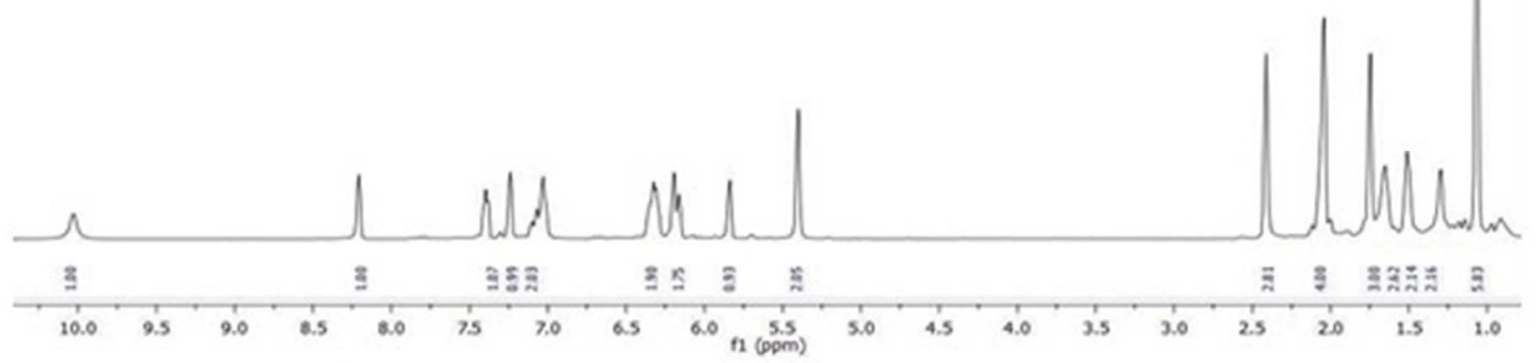

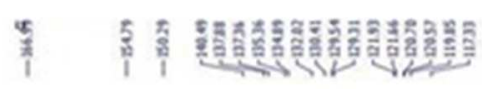

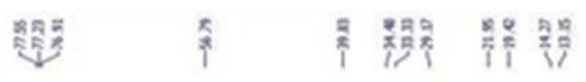<smiles>CC1=C(/C=C/C(C)=C/C=C/C(C)=C/C(=O)OCc2cn(-c3cc(Cl)ccc3C(=O)O)nn2)C(C)(C)CCC1</smiles>

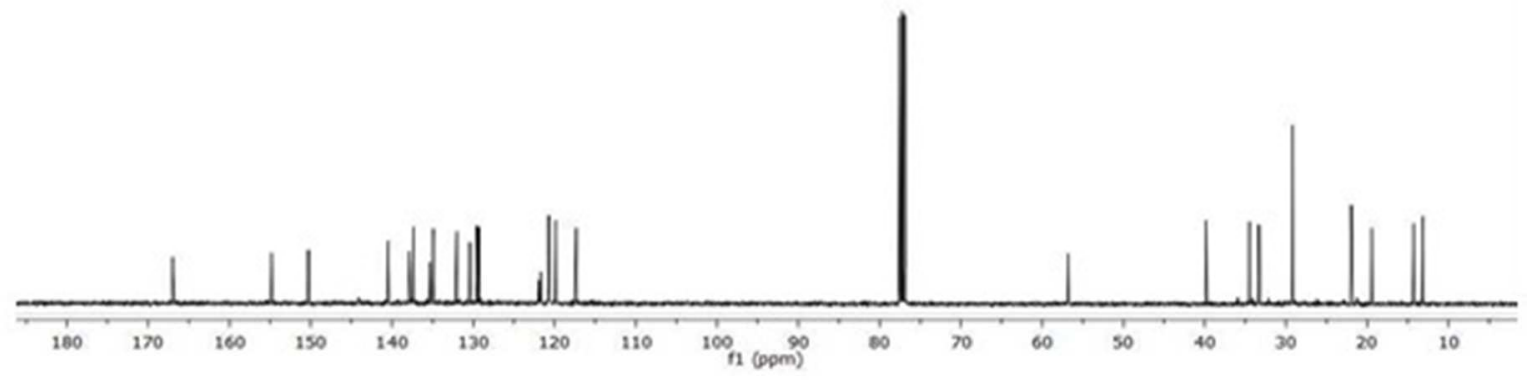


${ }^{1} \mathrm{H}$ NMR $\left(400 \mathrm{MHz}, \mathrm{CDCl}_{3}\right)$ and ${ }^{13} \mathrm{C} \mathrm{NMR}\left(100 \mathrm{MHz}, \mathrm{CDCl}_{3}\right)$ of $\mathbf{8 p}$

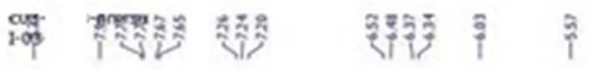

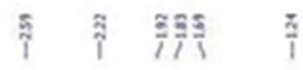

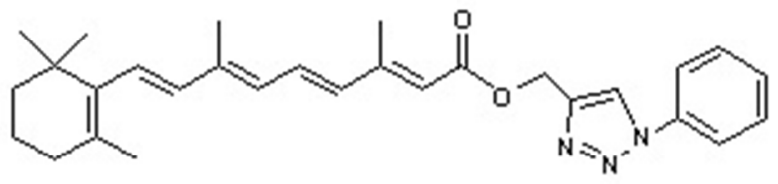

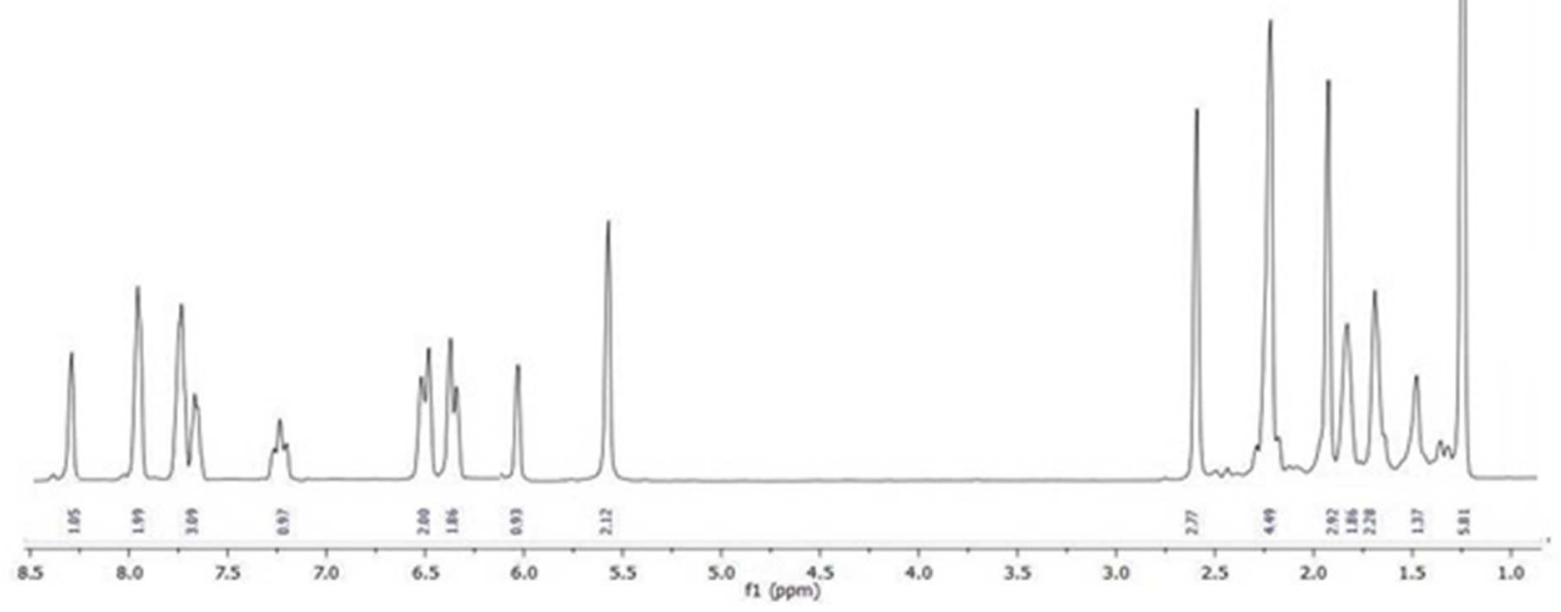

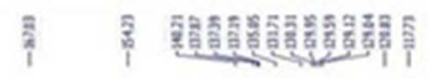

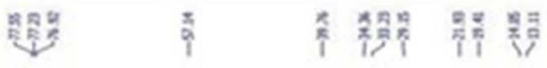<smiles>CC1=C(/C=C/C(C)=C/C=C/C(C)=C/C(=O)OCc2cn(-c3ccccc3)nn2)C(C)(C)CCC1</smiles>

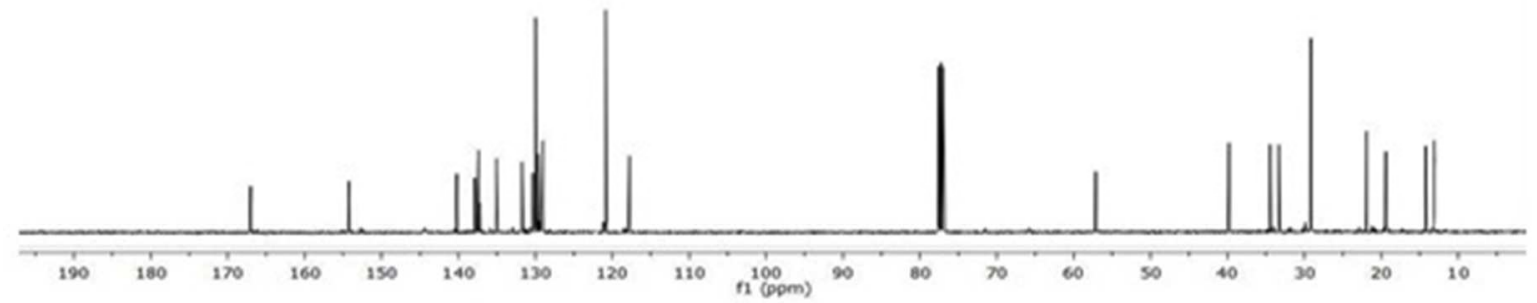


${ }^{1} \mathrm{H}$ NMR $\left(400 \mathrm{MHz}, \mathrm{CDCl}_{3}\right)$ and ${ }^{13} \mathrm{C} \mathrm{NMR}\left(100 \mathrm{MHz}, \mathrm{CDCl}_{3}\right)$ of $\mathbf{8 q}$

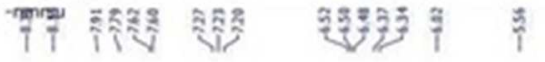<smiles></smiles>

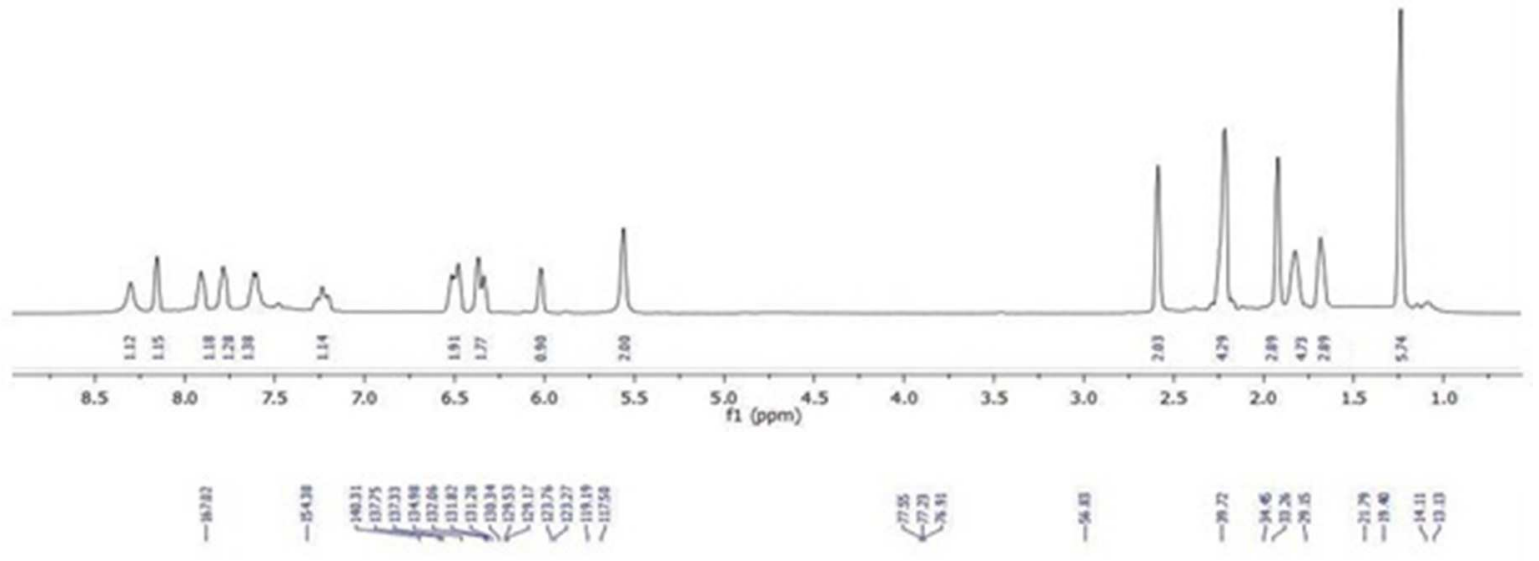<smiles>CC1=C(/C=C/C(C)=C/C=C/C(C)=C/C(=O)OCc2cn(-c3cccc(Br)c3)nn2)C(C)(C)CCC1</smiles>

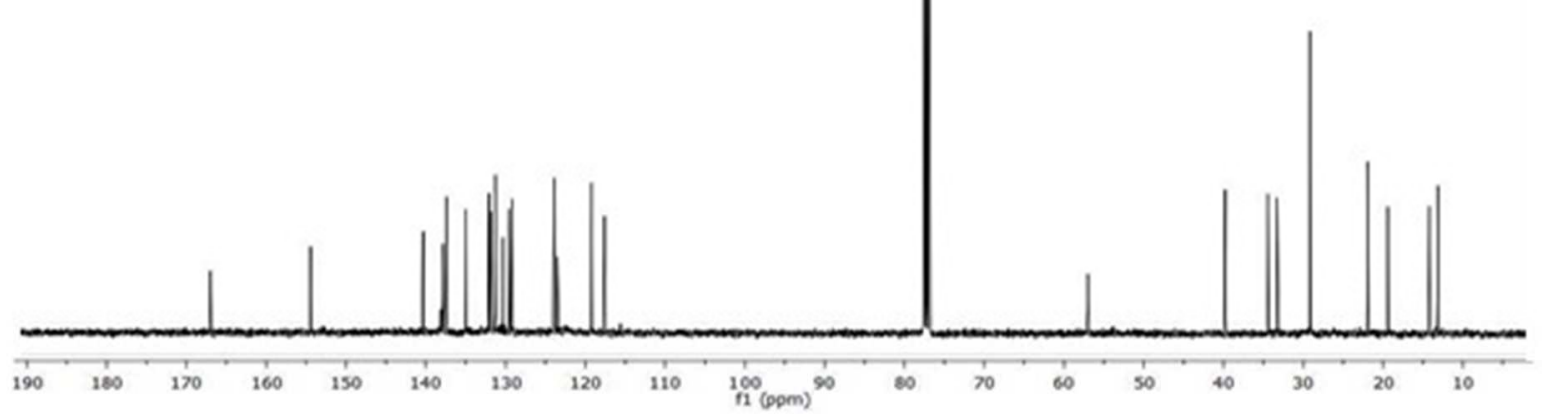


${ }^{1} \mathrm{H}$ NMR $\left(400 \mathrm{MHz}, \mathrm{CDCl}_{3}\right)$ and ${ }^{13} \mathrm{C} \mathrm{NMR}\left(100 \mathrm{MHz}, \mathrm{CDCl}_{3}\right)$ of $\mathbf{8 r}$
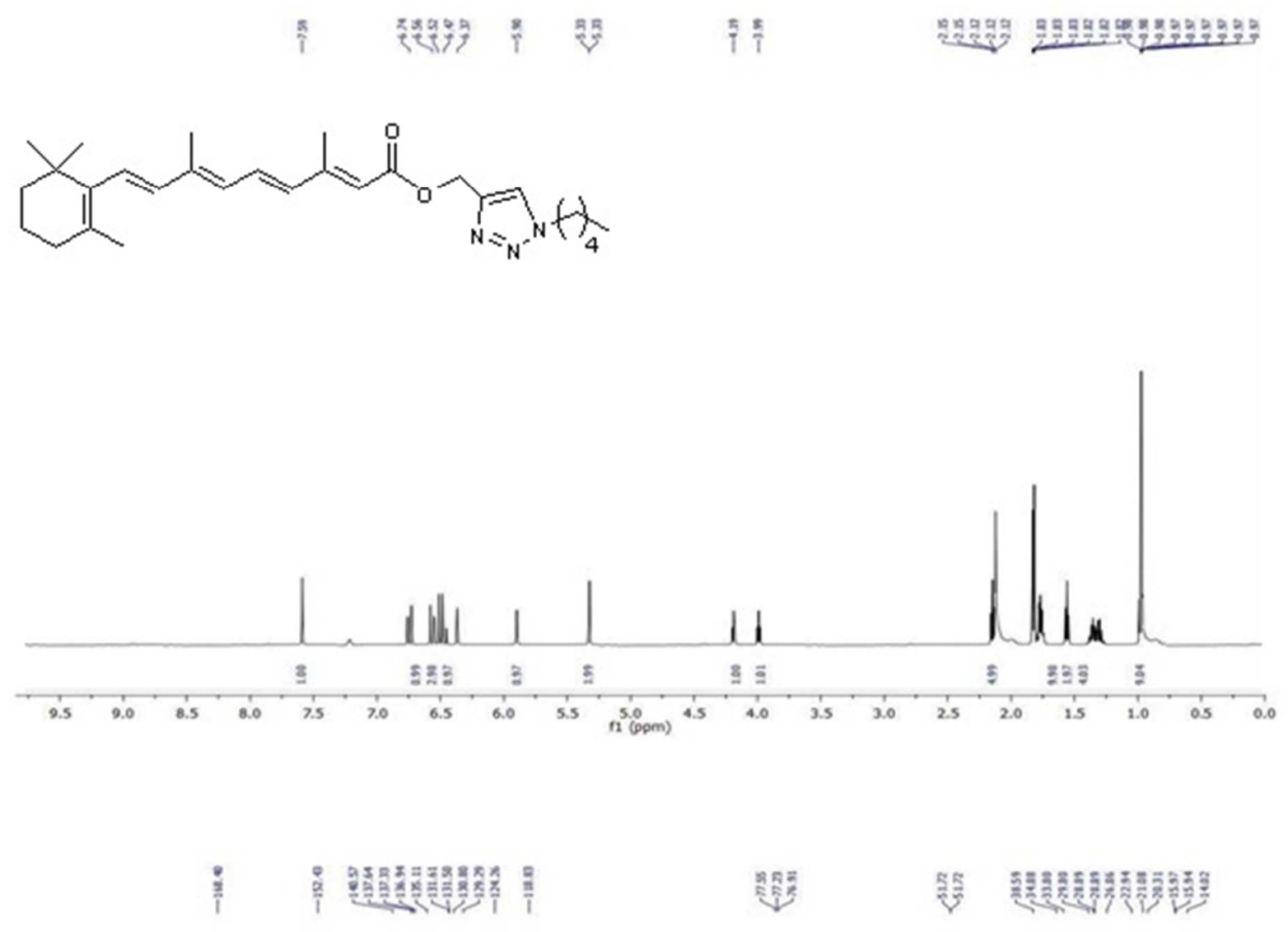<smiles>CC1=C(/C=C/C(C)=C/C=C/C(C)=C/C(=O)OCc2cn([Y5](F)(F)C3(C)CC3)nn2)C(C)(C)CCC1</smiles> 
${ }^{1} \mathrm{H} \mathrm{NMR}\left(400 \mathrm{MHz}, \mathrm{CDCl}_{3}\right)$ and ${ }^{13} \mathrm{C} \mathrm{NMR}\left(100 \mathrm{MHz}, \mathrm{CDCl}_{3}\right)$ of $\mathbf{8 s}$
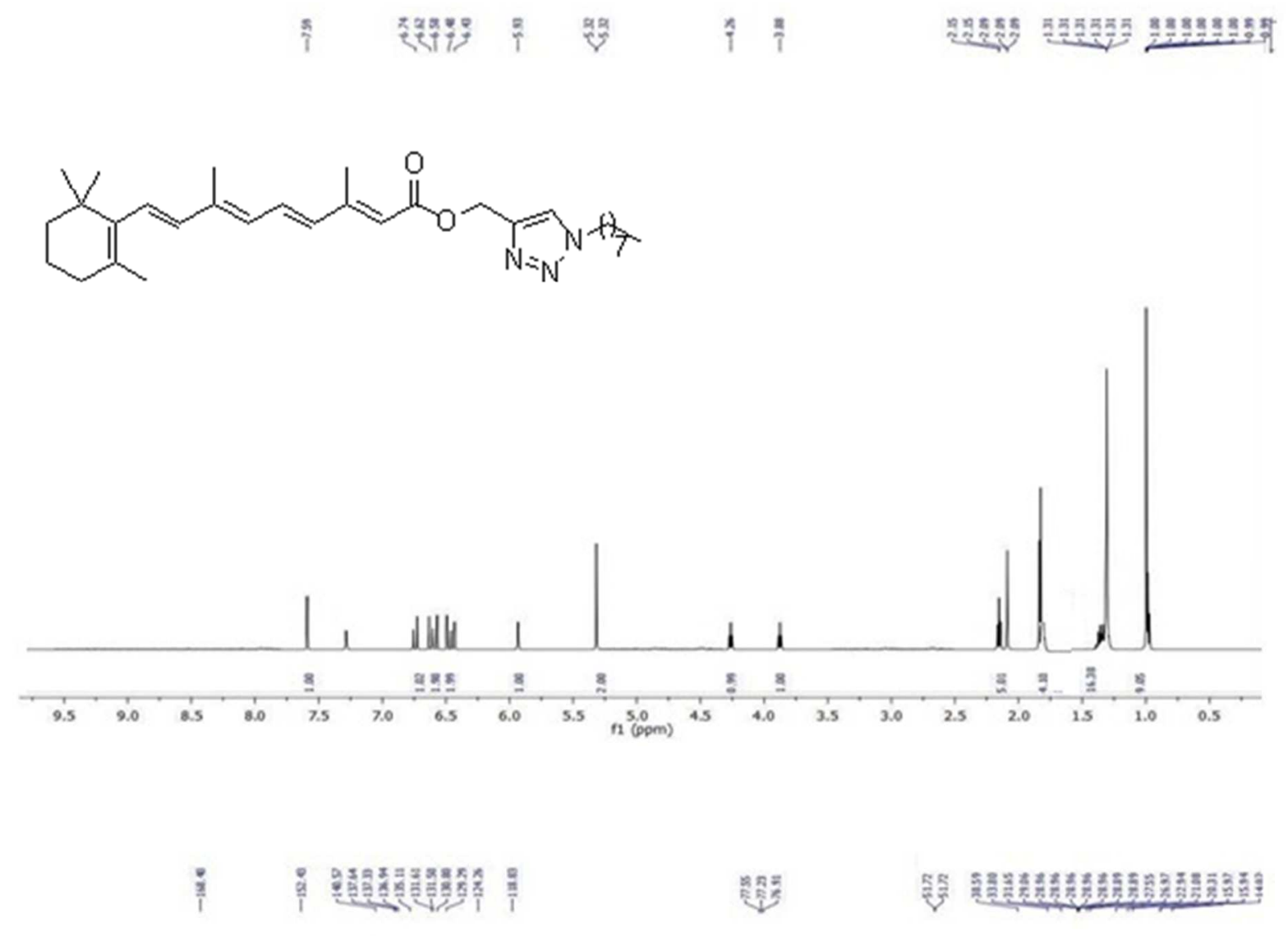<smiles>CC1=C(/C=C/C(C)=C/C=C/C(C)=C/C(=O)OCc2cn([14CH2])nn2)C(C)(C)CCC1</smiles>

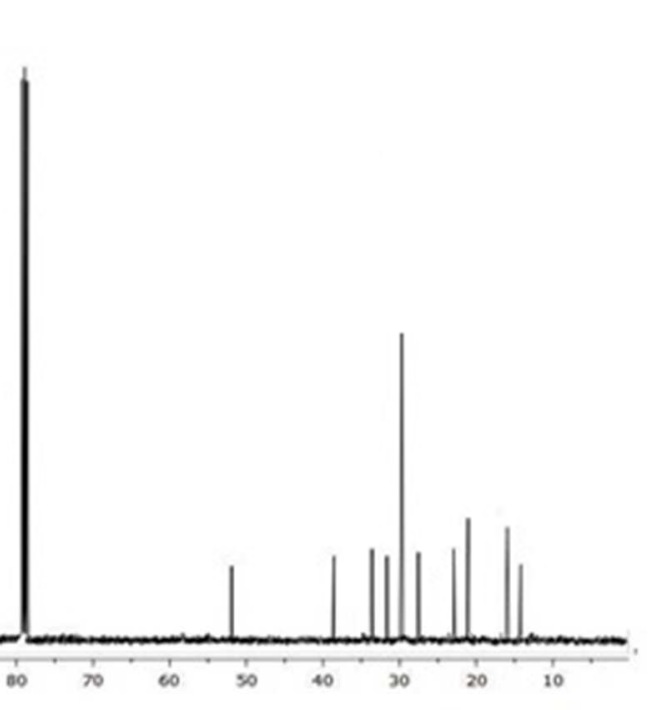


${ }^{1} \mathrm{H}$ NMR $\left(400 \mathrm{MHz}, \mathrm{CDCl}_{3}\right)$ and ${ }^{13} \mathrm{C} \mathrm{NMR}\left(100 \mathrm{MHz}, \mathrm{CDCl}_{3}\right)$ of $\mathbf{8 t}$
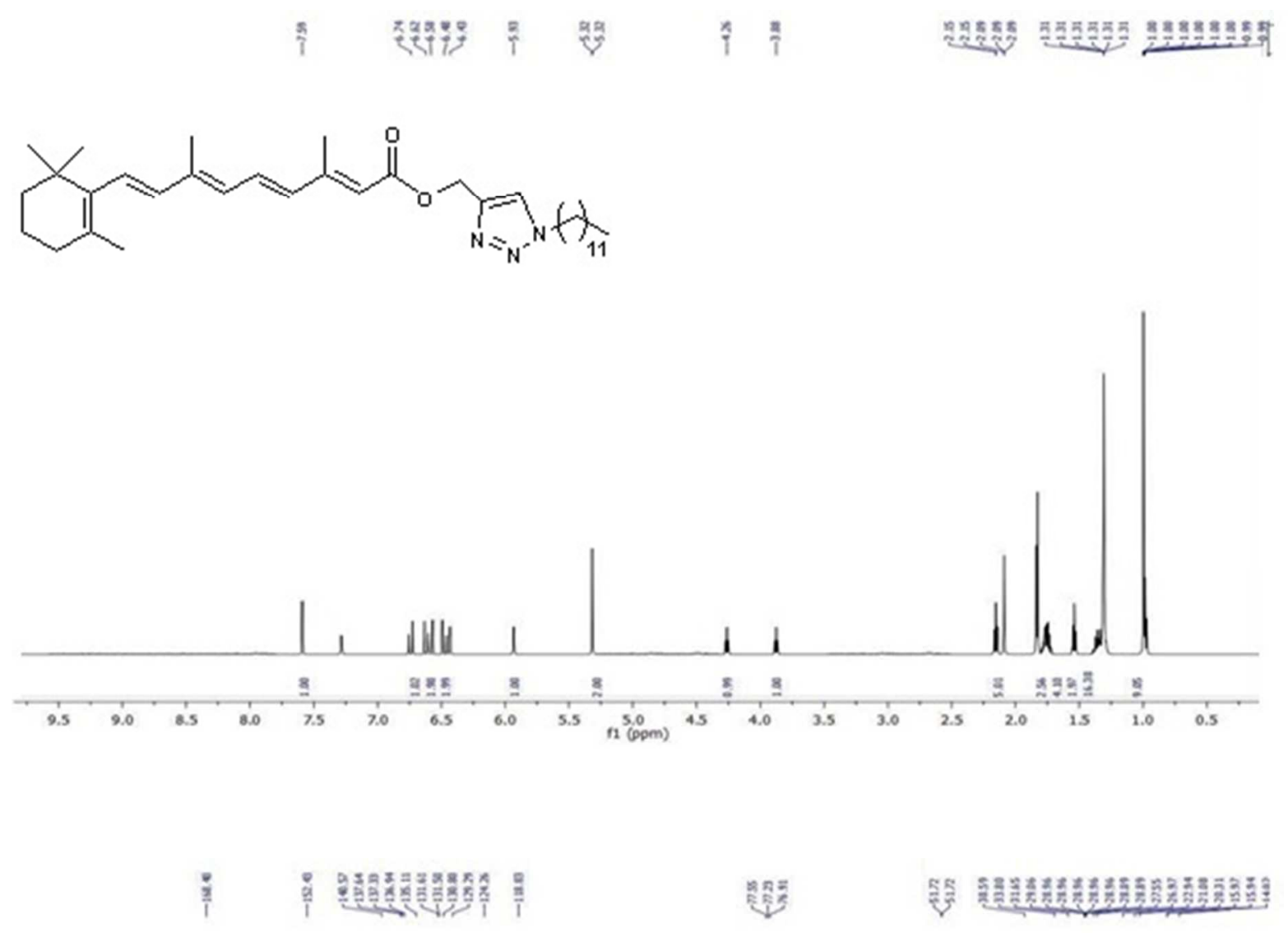<smiles>CC1=C(/C=C/C(C)=C/C=C/C(C)=C/C(=O)OCc2cn([Y17](C)(C)C)nn2)C(C)(C)CCC1</smiles>

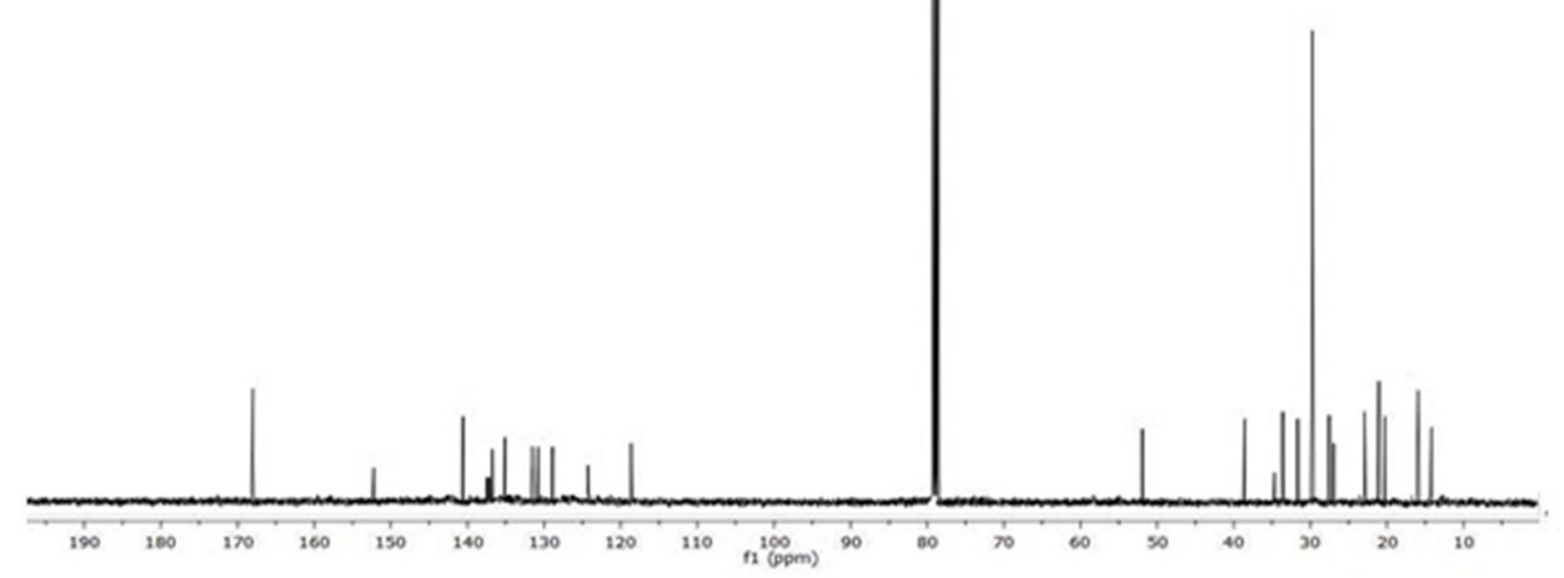


Mass spectrometric analysis of $R A, \boldsymbol{8 a}, \boldsymbol{8} \boldsymbol{e}, \boldsymbol{8} \boldsymbol{f}$ and $\boldsymbol{8 k}$ in cytosol: Neuro 2a cells were seeded in $60 \mathrm{~mm}$ tissue culture dishes and incubated with $10 \mu \mathrm{M}$ concentrations of RA, 8a, 8e, 8f and 8k for five days. Following incubation, the cells were scraped and pelleted down by centrifugation at $3000 \mathrm{rpm}$ for $5 \mathrm{~min}$. The cell pellets were lysed in $\mathrm{CHCl}_{3}: \mathrm{CH}_{3} \mathrm{OH}(1: 2, \mathrm{v} / \mathrm{v})$ centrifuged at $14000 \mathrm{rpm}$ for $15 \mathrm{~min}$ and the supernatant was transferred to the LC-MS sample vials for LC-MS analysis.

RA; HRMS calcd. $[\mathrm{M}+\mathrm{H}]^{+}=301.2162$; $\mathrm{LC}-\mathrm{MS}=301.14$

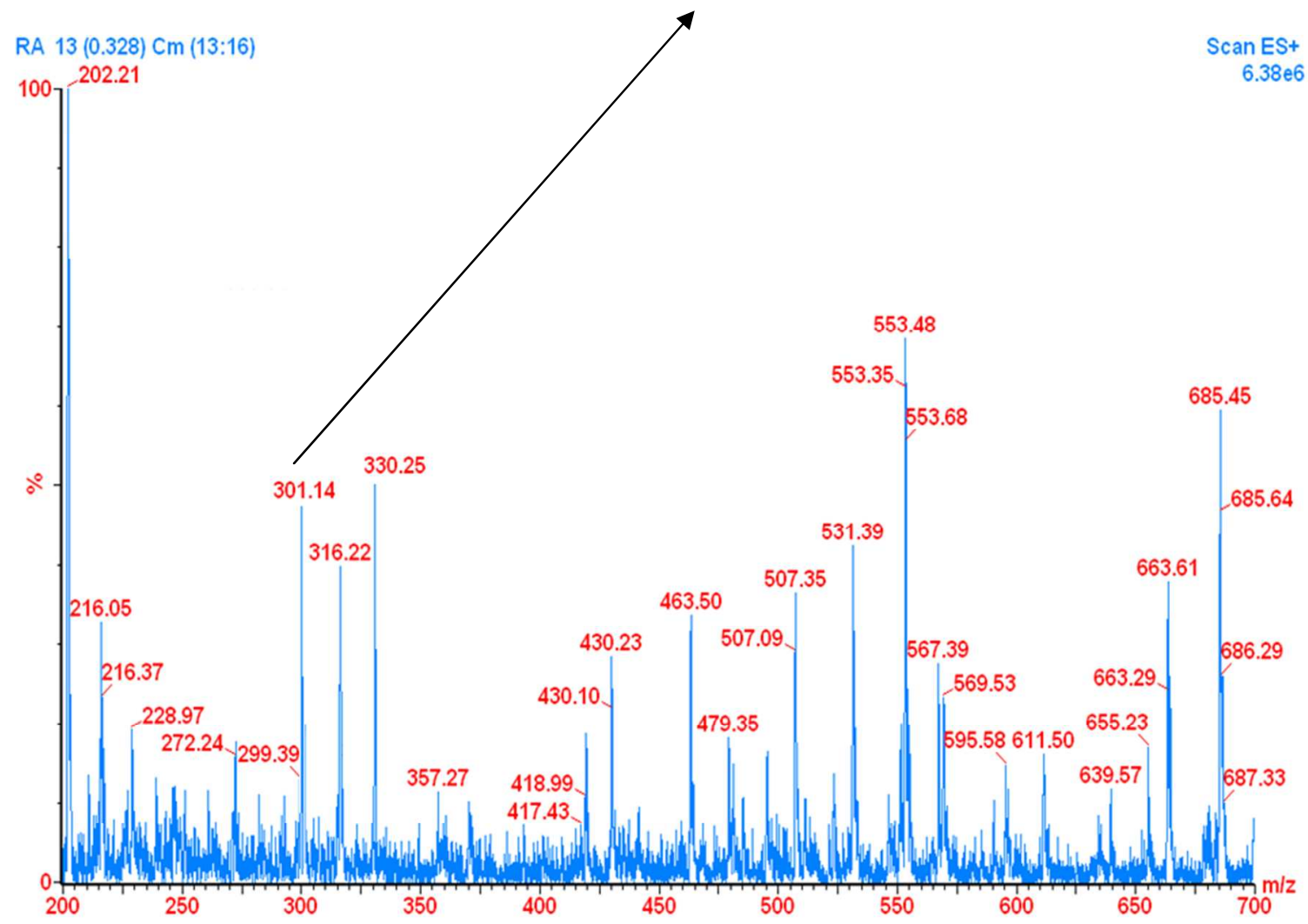


Compound 8a; HRMS calcd. $[\mathrm{M}]^{+}=502.2578 ; \mathrm{LC}-\mathrm{MS}=502.15$

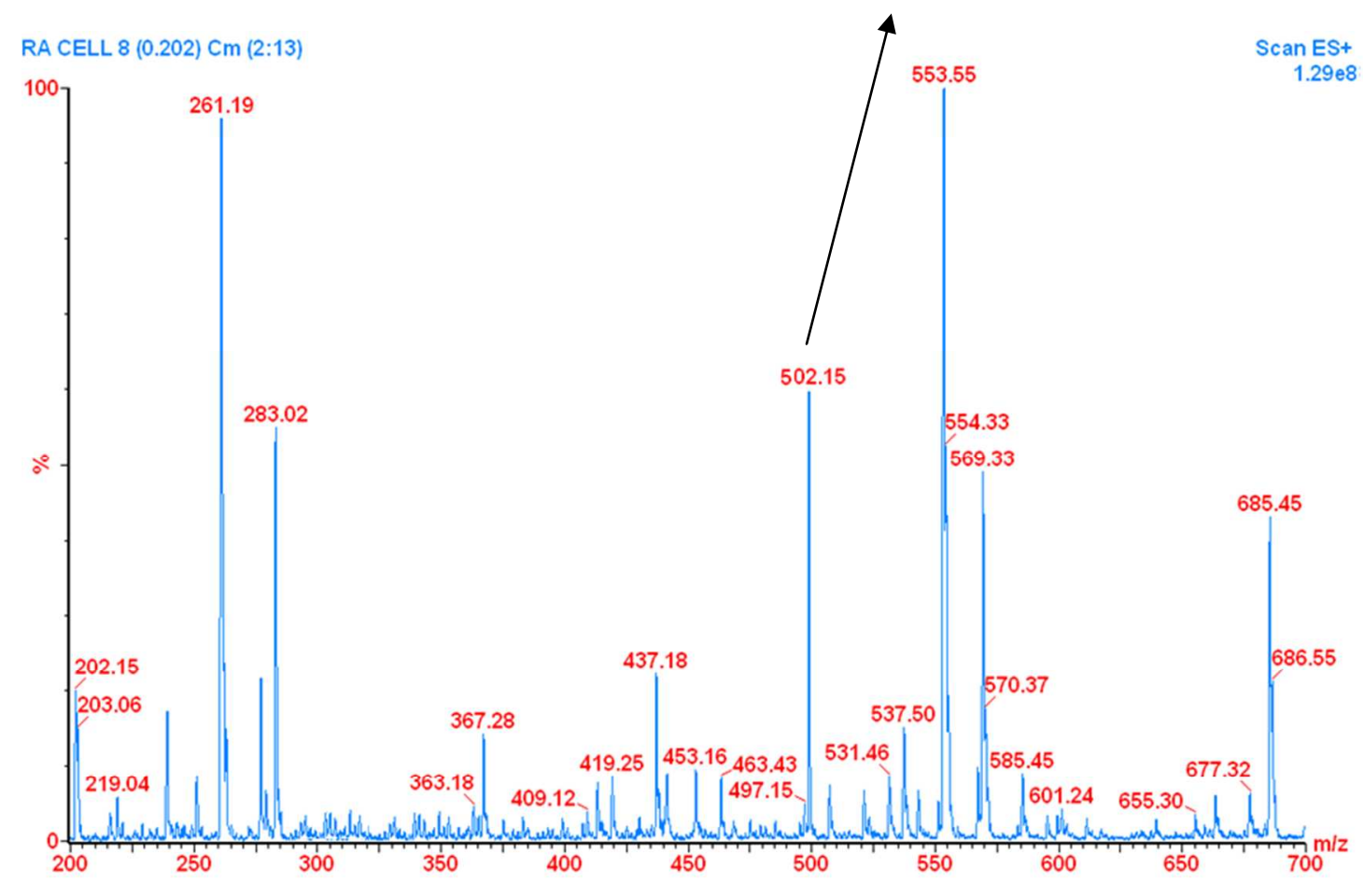

Compound 8e; HRMS calcd. $[\mathrm{M}]^{+}=475.2631$; $\mathrm{LC}-\mathrm{MS}=475.25$

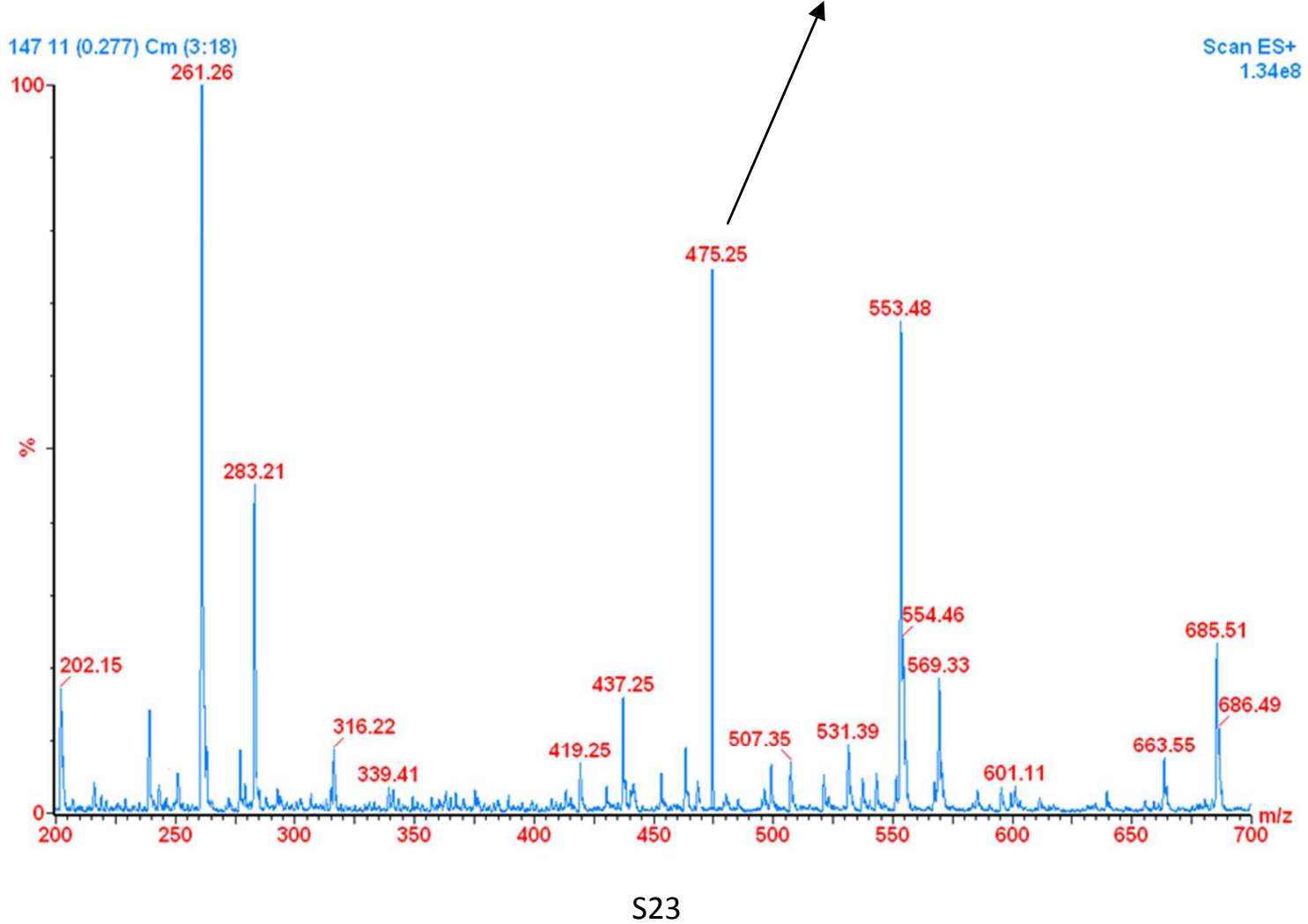


Compound 8f; HRMS calcd. $[\mathrm{M}+\mathrm{H}]^{+}=493.2539$; $\mathrm{LC}-\mathrm{MS}=493.26$

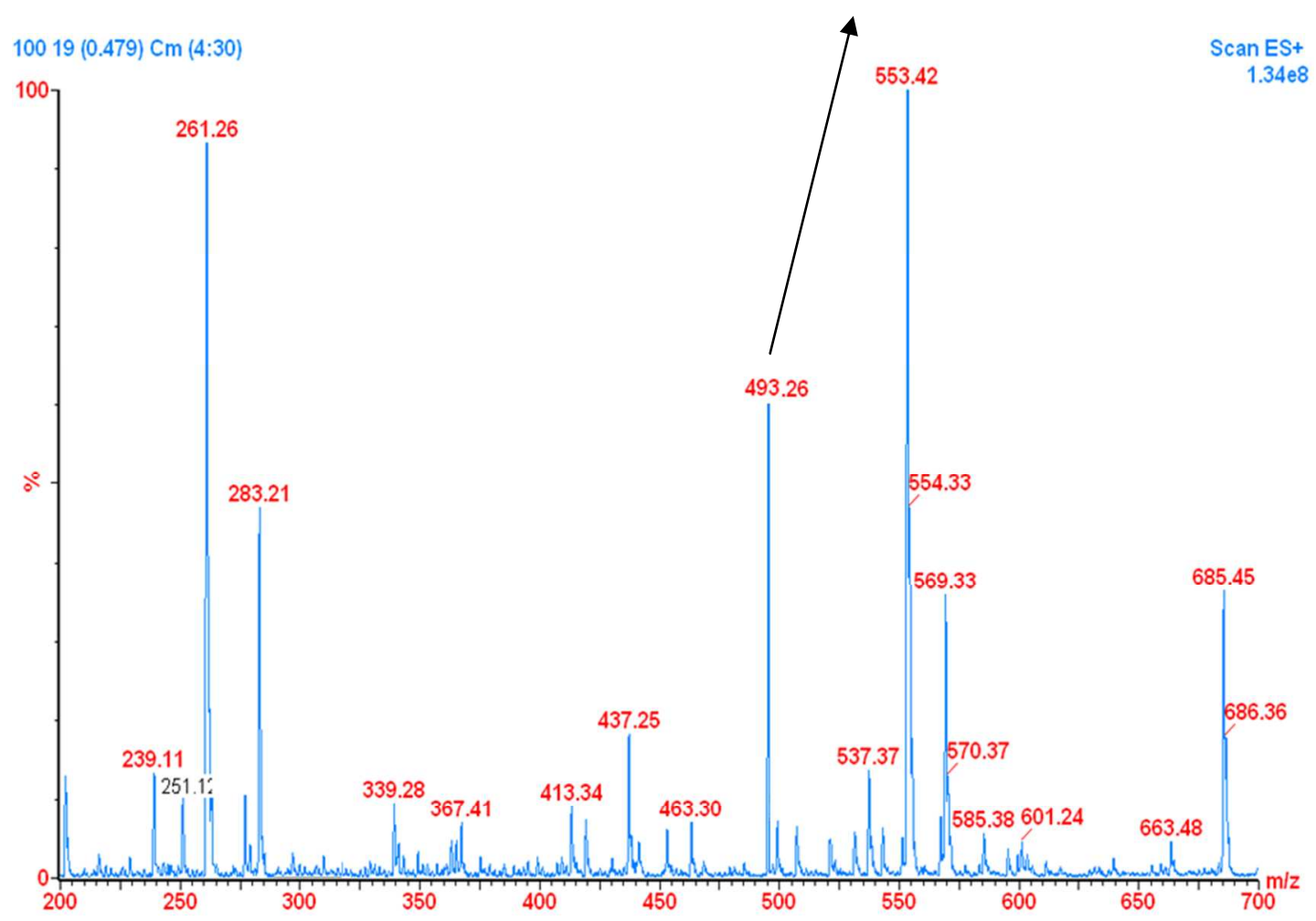

Compound 8k ; HRMS calcd. $[\mathrm{M}]^{+}=525.2601$; LC-MS $=525.22$

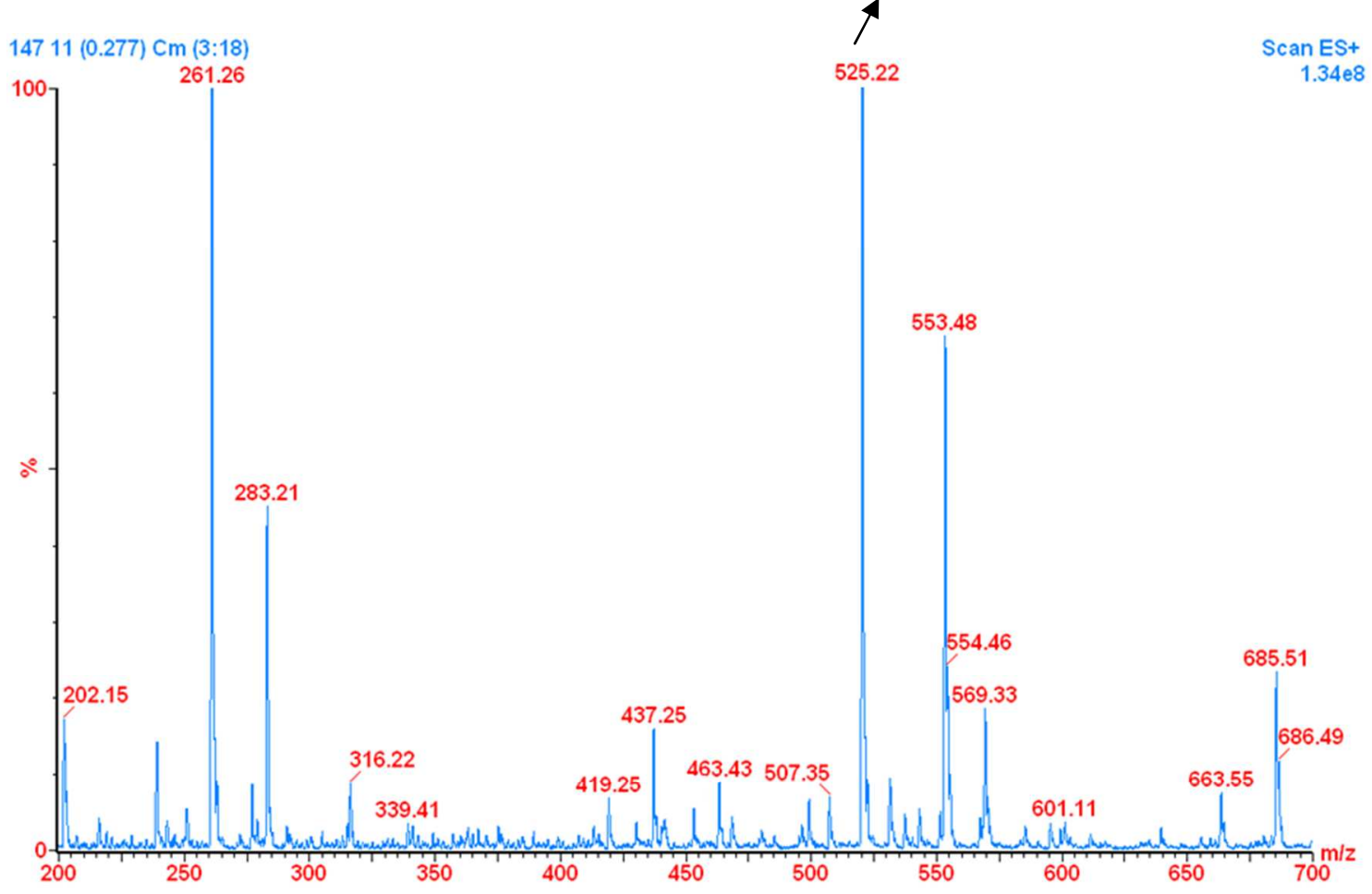

